\title{
Política i línies d’acció de la Generalitat al primer exili a través de l'anàlisi de les seves finances. França, 1939-1940
}

\author{
Xavier Puigarnau Torelló \\ Institut Universitari d'Història Jaume Vicens Vives \\ (Universitat Pompeu Fabra, Espanya) \\ orcid.org/0000-0001-6952-4820
}

Presentació: 21 abr. 2017 | Acceptació: 23 jul. 2018 | Publicació: 15 des. 2018

Citació recomanada: Puigarnau Torelló, Xavier. 2018. «Política i línies d’acció de la Generalitat al primer exili a través de l'anàlisi de les seves finances. França, 1939-1940». Dictatorships \& Democracies. Journal of History and Culture 6: 89-136. doi: https://doi.org/10.7238/dd.voi6.3148.

Resum: L’anàlisi de les línies d'acció i de les prioritats polítiques de la Generalitat de Catalunya a través de l'estudi de les seves finances ens aporta una imatge més clara del seu paper en el primer exili francès. Les dificultats per aconseguir recursos, causades per la permanent incapacitat d'arribar a un acord de finançament amb el Govern espanyol a l'exili, van fer que les polítiques de suport a les institucions, a la cultura i a l'assistència als refugiats catalans de base es despleguessin amb resultats minsos a curt termini i mediocres a mitjà termini. El suport de la Generalitat a la concentració física dels principals polítics i intellectuals catalans va ser prioritari i on va esmerçar els seus millors recursos, especialment a la residència de Montpeller. La dependència econòmica de la Generalitat respecte a les institucions republicanes a l'exili va afeblir la figura del president Companys, va contribuir amb força al seu aïllament i va facilitar, finalment, la dispersió dels exponents del catalanisme polític.

Paraules clau: exili, Generalitat de Catalunya, finances

Policy and Action Lines of the Generalitat of Catalonia in the First Exile through the Analysis of its Finances. France, 1939-1940

Abstract: The analysis of the Generalitat of Catalonia's financials in its first exile gives us a better picture of its role during that period. Through it, we can better understand its line of action and its political priorities in the first steps of the French exile. The permanent incapacity of achieving an economic deal with the Spanish Government set the institution in financial turmoil. That was reflected by the weak amount of supported exiled politicians, the poor promotion of cultural endeavours and the incapacity in assisting the masses of Catalan refugees. The support of the Catalan Government to the concentration of the Catalanist political and intellectual leaders came to be the main priority. Following this, they especially dedicated their best resources to the Residence of Montpellier, for intellectual and political leaders. The Generalitat of Catalonia depend- 
ed economically to excess on the exiled Spanish republican institutions. This situation led to Companys lacking in political influence and the increasing isolation of his figure. Keywords: exile, Generalitat of Catalonia, financials

Com ens recorda Mercè Morales en el seu darrer estudi sobre la Generalitat a l'exili, ${ }^{1}$ després de la caiguda de Catalunya el febrer del 1939, els membres més destacats de la Generalitat i alguns parlamentaris van aconseguir establir-se lliurement a les àrees de París i de Perpinyà. Per contra, la majoria d'exiliats catalans de base van ser internats en una àmplia xarxa de camps de concentració establerts per les autoritats franceses a la zona fronterera. Aproximant-nos a aquest marc, es pot observar com els darrers anys han estat notablement fructífers en el camp de la historiografia dedicada a l'exili dels catalans després de la Guerra Civil. Han vist la llum nombroses monografies, reedicions de memòries, biografies i dietaris que cerquen de copsar els primers moments del que podríem anomenar "protoexili", l'exili més líquid, inestable, però a la vegada, paradoxalment, potser el més fàcil d'encapsular. ${ }^{2}$ Parallelament, les possibilitats d'accedir a la consulta de fonts primàries relatives a aquest període han anat en augment. El fet de poder explorar amb profunditat, buscant les restes de la seva burocràcia, els documents de la Generalitat al primer exili de l'anomenat "fons d'Artea" de l'Arxiu Nacional de Catalunya (ANC) o els documents de Josep Tarradellas custodiats a l'Arxiu Montserrat Tarradellas i Macià de Poblet (AMTM) ens permet accedir a la realitat del moment des d'una nova perspectiva, podríem dir, més objectiva i directa.

Entre els diferents aparats administratius bastits per la Generalitat de Catalunya a França al primer exili, es va generar una quantitat gens negli-

1 Mercè Morales Montoya, La Generalitat de Josep Irla i l'exili polític català (Barcelona: Editorial Base, 2014), 49-54.

2 Montserrat Roig (1977) o Daniel Díaz Esculies (1933) han denunciat les condicions inhumanes que van patir els refugiats catalans als camps, i Francesc Vilanova (1995), per la seva banda, ha traçat una visió general dels trets que ens ajuden a entendre el context polític general a partir dels escrits de Carles Pi i Sunyer. Maria Campillo (1994), Julià Guillamon (2005, 2008) o Montserrat Corretger (2006), entre d'altres, han treballat els intellectuals i artistes de més renom de l'exili. Seguint les petges de Josep Benet (2005) en els seus estudis sobre Companys, també s'han publicat nombroses biografies de polítics catalans exiliats de més o menys volada. La bibliografia sobre el primer exili català és extensa i variada, però sovint manquen monografies detallades sobre aspectes concrets de caràcter més organitzatiu o de perfil econòmic. 
gible de documents de caràcter burocràtic, que faciliten entendre quines van ser les seves prioritats en el camp de la promoció cultural i en el sosteniment de les institucions, i els esforços invertits en l'àmbit de l'assistència social en territori francès. Però, què s'ha explicat fins ara sobre la realitat política, organitzativa, administrativa i econòmica de la Generalitat durant aquells mesos a França? Podríem respondre que se n'ha explicat molt, però el cert és que hi ha molts aspectes que no són prou clars, més aviat sovint són confusos, de vegades fins i tot contradictoris o boirosos.

Immediatament després del traspàs a França, la Generalitat de Catalunya, ${ }^{3}$ fragmentada en el seu Consell Executiu, va optar per centrar tota la seva activitat en la Conselleria de Presidència, que, en la figura del president Companys, podia donar esperances d'una certa estabilitat i solidesa. Contràriament al que podria semblar, els seus líders es van esforçar no tant a preservar el partit com les institucions. ${ }^{4}$ Així, la salvaguarda de la cultura es va traduir en la creació de la Fundació Ramon Llull. ${ }^{5}$ L'activitat política, en canvi, es va centrar, bàsicament, a prestar suport a Companys com a representant de les institucions catalanes. D'altra banda, la tasca assistencial va consistir a treballar a favor dels catalans desplaçats, dels internats en els camps de concentració i dels que vivien a fora, gràcies als organismes propis a Perpinyà i a París, però també per mitjà de la representació dels catalans a les institucions d'ajuda estatals.

La posició política estava clarament definida: es tractava de preservar una àrea de poder i de gestió sobre el collectiu catalanista a França, encara que s'hagués perdut el territori sobre el qual exercir-los. ${ }^{6}$ És cert que el president Companys rebé durant aquells mesos fortes pressions: el menyspreu de comunistes i anarquistes, els atacs constants de les forces catalanistes dissidents — també des del seu mateix partit—així com

3 En tot moment parlarem dels polítics anomenats "catalanistes republicans", majoritàriament d'ERC i d'Acció Catalana Republicana, no pas dels comunistes del PSUC ni dels anarquistes.

4 Daniel Díaz Esculies, El catalanisme polític a l'exili (1939-1959) (Barcelona: Edicions la Magrana, 1991), 20-23.

5 La Fundació Ramon Llull va ser una plataforma d'acció multifuncional que, tot i que inicialment va ser creada per fomentar la cultura catalana, també va servir, en diverses etapes de la seva existència, com a paraigua legal d'altres tasques de caràcter polític $\mathrm{o}$ assistencial.

6 Joan Sauret, L'exili polític català (Barcelona: Editorial Aymà, 1979), 37. Aquest autor dibuixa el marc clàssic dels principals responsables de la política catalanista exiliats a França durant aquest període. 
l'anorreament dels líders del Govern republicà. Probablement, el punt més dèbil de Lluís Companys era la incapacitat econòmica per poder ajudar a tothom i estructurar una bona xarxa d'addictes i convencibles que abastés, amb sentit d'unitat nacional, sectors amplis, majories, sense por de deixar fora els comunistes. Aprofundir en aquest camp ens fa percebre de manera més o menys clara una línia contínua que coincideix amb l'estreta vinculació entre el nivell assistencial-financer i el nivell polític o de joc de poder.

El febrer del 1939 Companys considerava dissolt el Govern, perquè no hi havia cap territori que el sostingués. Sense Parlament ni Govern havia de conservar d'alguna manera la Presidència de la Generalitat com a òrgan aglutinador de tots els catalans. Una bona part d'ERC li donava suport i el PSUC no en qüestionava l'autoritat, tot i que reclamava una reunió de govern a l'exili que mai no es va arribar a produir. Per indicació expressa de Presidència, els dirigents d'ERC es van dedicar a promoure la creació del Consell Nacional, que va acabar de prendre forma l'abril del 1940. Aquesta institució, de caràcter consultiu més que no pas polític, havia d'ajudar a sortir del collapse en què s'havia estancat l'exili català i fer de govern oficiós de Catalunya. La idea era trobar una fórmula que donés suport a Companys en la seva tasca assistencial, cultural i política excloent-hi de manera explícita el PSUC per tal d'aïllar-lo.7 La iniciativa es va materialitzar inicialment en una enquesta en el si d'ERC, sobretot entre els seus quadres de comandament, que havia de revelar el suport que tenia Companys en aquell moment. Les respostes del Ple del Consell Directiu d'ERC es van decantar majoritàriament per la creació del Consell Assessor de Presidència, que no havia de ser un òrgan de caràcter estrictament polític, sinó que entre els seus membres hi havien de figurar

7 Vegeu el document de petició per a la formació del Consell Nacional enviat a Josep Tarradellas de part d'uns cinquanta militants catalanistes republicans, signat a Perpinyà el 20 d'abril de 1939, en el qual es demana explícitament que el Consell Nacional estigui «format per representants de tots els grups nacionals, amb exclusió d'aquells que depenguin directament o indirectament d'organitzacions alienes al nostre moviment nacional», 5.6.1, doc. 2-3, Fons Generalitat de Catalunya a l'exili, ANC. Paga la pena remarcar que la data de redacció és certament primerenca, atès que no es va constituir el citat organisme fins dotze mesos després. 
elements de pes cultural i personalitats representatives. ${ }^{8}$ Els promotors insistien en la idea que no es tractava de crear un nou govern català sinó de fer un «organisme que representés Catalunya a l'exili»` $\mathrm{i}$, alhora, que fos capaç d'administrar els recursos de manera menys personalista, qüestió que era l'origen de moltes de les crítiques rebudes..$^{10} \mathrm{El}$ punt de partida del Consell va ser un nucli estable format per ERC, ACR i Estat Català, amb Unió Democràtica, que, tanmateix, estava poc interessada a entrar-hi. A finals d'abril del 1940 es va aprovar la constitució del Consell Assessor de Presidència, integrat per un president, Pompeu Fabra, i els membres següents: Santiago Pi i Sunyer, Josep Pous i Pagès, Antoni Rovira i Virgili i Jaume Serra Húnter. ${ }^{11}$ Malgrat l'aparent consens i el desencallament que suposava per a la política catalana a l'exili la creació del Consell Nacional de Catalunya, no va arribar a ser mai operatiu a França a causa de l'ocupació alemanya. Aquest agitat període d'establiment a França de persones, partits i institucions configura un escenari canviant, que dificulta la comprensió de l'acció política i de la manera en què se sustentava, és a dir, de com s'organitzava administrativament, d'on es treien els recursos i en què s'empraven.

\section{Origen dels recursos de la Generalitat de Catalunya al primer exili}

Quan Juan Negrín fou conscient que la República podia ser destruïda militarment per les forces franquistes, seleccionà els seus collaboradors més fidels - Francisco Méndez Aspe, Jerónimo Bugeda, José Prat i Rafael Méndez - i els encarregà una llista dels actius que encara eren propietat del Govern de la República amb la idea d'enviar-los a França per cobrir les

8 Carta de Carles Pi i Sunyer a Tarradellas del 13 de desembre de 1939, citada per Francesc Vilanova, Als dos costats de la frontera: Relacions polítiques entre exili i interior a la postguerra (1939-1948) (Barcelona: Publicacions de l'Abadia de Montserrat, 2001), 67.

9 Sauret, L'exili polític català, 38.

10 Morales Montoya, La Generalitat de Josep Irla..., 80-91. Moltes crítiques provenien dels mateixos membres més propers al poder, com ara el collaborador de Josep Tarradellas, Josep Fontbernat, tal com ens recorda Joan Esculies a la biografia Josep Fontbernat: Conseller de Tarradellas (Barcelona: Fundació Irla, 2017), 95.

11 Carta de Tarradellas a Carles Pi i Sunyer del 20 d'abril de 1940, citada per Vilanova, Als dos costats de la frontera..., 78. 
necessitats dels futurs exiliats. ${ }^{12}$ En aquest conjunt de béns s'inclogueren joies, or, plata, valors financers i possessions de persones solvents que havien marxat de l'Espanya republicana, així com diverses obres d'art i joies de l'Església. ${ }^{13}$ Entre l'octubre del 1938 i el febrer del 1939 aquests objectes foren empaquetats i carregats en camions que es detingueren a Figueres i a pobles de la contrada esperant el moment i les condicions adients per creuar la frontera. Juan Negrín i el seu govern no es conformaren d'acumular els recursos que depenien directament del Ministeri d'Hisenda republicà, sinó que procuraren d'atreure cap a ells tots els fons possibles. Les institucions d'autogovern català no quedaren al marge d'aquestes operacions i, en els darrers mesos de la contesa, la Generalitat hagué de posar a disposició del Govern central republicà tots els recursos que posseïa, a fi d'ajudar a capgirar la direcció funesta que estaven prenent les hostilitats.

Sota la responsabilitat de Josep Tarradellas, ${ }^{14}$ es va fer un inventari detallat d'aquests recursos, en què consten les dates de traspàs i les quantitats entregades. ${ }^{15}$ Alguns són productes financers de procedència i condició molt diversa, i de valor actual desconegut: accions de companyies com La Unión y el Fénix Español, obligacions d'entitats públiques com l'Ajuntament d'Anvers o del canal de Panamà, o deute públic del Japó, de l'Uruguai, de Xile o del Brasil, entre molts altres valors internacionals. La relació continua amb diverses tones de metalls preciosos convertits en numerari o en lingots, bàsicament de plata, d'or i de platí, així com joies de diversa procedència entregades al Govern republicà. Finalment, inclou

12 Diversos autors exalcen darrerament la figura de Juan Negrín durant la guerra i també la posició que va adoptar davant l'atenció als refugiats. Vegeu Gabriel Jackson i Víctor Alba, Juan Negrín (Barcelona: Ediciones B, 2004), 141-142; Enrique Moradiellos, Don Juan Negrín: Una biografía de la figura más difamada de la España del siglo xx (Barcelona: Ediciones Península, 2006), 25, i Paul Preston, El final de la guerra (Madrid: Editorial Debate, 2014).

13 Carles Pi i Sunyer, La Guerra, 1936-1939: Memòries (Barcelona: Editorial Pòrtic, 1986), 223.

14 Enrique Moradiellos defensa que, atès que la Generalitat s'havia apropiat dels béns per fer front a les competències que havia usurpat de l'Estat en un moment d'emergència, les autoritats republicanes tenien tot el dret a tornar-les a reclamar un cop recuperades les competències. Moradiellos, Don Juan Negrín..., 238.

15 Relació de béns traspassats, febrer de 1939, A11Co1E01Do1, AMTM. Coincideixen parcialment amb la relació que detalla Francisco Gracia Alonso i Gloria Munilla a El tesoro del 'Vita': La protección y expolio del patrimonio histórico-arqueológico durante la Guerra Civil (Barcelona: Edicions de la Universitat de Barcelona, 2013), 143. 
diners corrents en pessetes republicanes, que van ser ingressats al Banc d'Espanya a diferents sucursals del territori espanyol o fins i tot a França. Resulta difícil de calcular-ne el valor, però, segurament, s'hauria pogut vendre al mercat francès per diverses desenes de milions de francs francesos (d'ara endavant, "francs"). ${ }^{16}$

Així doncs, desposseïda dels seus béns, la Generalitat de Catalunya no va tenir més remei que recórrer a fonts de finançament alternatives, principalment de les institucions de l'Estat republicà a l'exili i de la caritat dels francesos. Per dur a terme qualsevol iniciativa que es plantegés des de les instàncies polítiques del catalanisme exiliat calien mitjans econòmics; tanmateix, els recursos de la Generalitat, per insistència de Negrín, van ser, com hem vist, forçadament transferits al Govern central les darreres setmanes de la contesa, teòricament amb la intenció d'establir un sistema de repartiment equitatiu basat en la fórmula del Consell dels Cinc Presidents (compost pels presidents de la República, del Govern central, de les Corts, de la Generalitat i del Govern autònom basc). Sense marge real per oposar-s'hi i àdhuc pensant que les autoritats franceses no els haurien permès creuar la frontera amb els fons esmentats, els integrants del Govern de la Generalitat van considerar que aquesta fórmula era un instrument adient per resoldre la qüestió econòmica a l'exili, i així sembla que ho ha entès una bona part de la historiografia actual. ${ }^{17}$ En aquest context, la Generalitat de Catalunya va passar a dependre econòmicament i, per tant, políticament del Govern central republicà a l'exili.

16 Segons Sánchez Asiaín, l'equivalent en francs del febrer del 1939 és el següent: 100 pessetes republicanes serien 2,10 francs i 117 pessetes, 1 lliura esterlina. Així doncs, 1 lliura esterlina equivaldria a uns 2,46 francs. Vegeu José Ángel Sánchez Asiaín, La financiación de la Guerra Civil española (Barcelona: Editorial Crítica, 2012), 955. Vegeu, especialment, els quadres de «Cotización oficial de la peseta del Gobierno Republicano», ibídem, 951-952, i «Cotización comparada de las dos pesetas», ibídem, 954-955. Altrament, per fer-nos una idea de l'equivalent actual es pot consultar, també, el testimoni d'Artur Bladé, que comenta com el juliol del 1939 el nivell de vida es podria establir de la manera següent: un quilo de pa costava 3,75 francs; un litre de llet, 1,40 francs, i un quilo de patates, 2 francs. Vegeu Artur Bladé Desumvila, L'exiliada (Dietari de l'exili, 1939-1940) (Barcelona: Editorial Pòrtic, 1976), 144. Salvant les distàncies, no sembla gens allunyat de la realitat que el franc del 1939 equivalgués aproximadament a 1 euro del 2018.

17 El mateix conseller de Cultura, Carles Pi i Sunyer, que també ho va ser de Finances, afirmava que «un acte de revolta contra les disposicions del Govern de la República en aquell moment hauria estat catastròfic» i que «tampoc no tenien cap possibilitat de dur-lo a terme», Carles Pi i Sunyer, $L a$ Guerra 1936-1939: Memòries (Barcelona: Editorial Pòrtic, 1986), 224-225. 
Molt abans del final de la contesa, el Govern republicà, a petició del Govern francès, ja havia creat el 1937 un servei oficial per atendre els refugiats provinents de les zones ocupades del nord, que es denominà Servicio de Emigración de los Republicanos Españoles (SERE).$^{18}$ El gener del 1939 fou rescatat en les seves funcions després de la caiguda de Tarragona, amb la intenció d'assentar els refugiats procedents de Catalunya que, presumiblement, passarien a França poques setmanes més tard. ${ }^{19}$ Arran d'això, en el decurs d'una entrevista i en cartes posteriors, Negrín comunicà d'una manera poc clara al president de la Generalitat la reactivació del SERE, encara que no fos el que havien acordat a Figueres..$^{20}$ Malgrat la negativa rotunda inicial de l'Executiu espanyol d'acceptar un repartiment dels fons en el marc d'una política de descentralització semblant a la que era habitual abans de la caiguda de Catalunya, i la consegüent queixa de Companys, ell, seguint les ordres de Negrín, redactà la seva proposta alternativa -és conegut que solia acabar les desavinences amb un «Esto que usted me cuenta, póngalo por escrito y ya lo veremos». El document resultant, intencional i programàtic, perfilà les línies mestres de la política de la Generalitat del primer exili i la intenció que es continués respectant el règim autònom de Catalunya propi de l'Estat republicà segons la Constitució del 1931. ${ }^{21}$ Per garantir-ho, se sollicità a l'Executiu espanyol que auxiliés els refugiats catalans atenent a un principi de descentralització, que es concretaria encarregant aquesta tasca a un òrgan autònom dins del conjunt de l'obra de l'Estat i al qual, per tant, sotmetria a un rigorós

18 José María del Valle, Las instituciones de la República española en el exilio (París: Éditions Ruedo Ibérico, 1976), 33.

19 Els recursos del SERE la primavera del 1939 són objecte de discussió. Mentre Abdón Mateos parla de 26 milions de dòlars (uns 978 milions de francs del febrer del 1939), José Ángel Sánchez Asiaín afirma que, quan la policia francesa va inspeccionar els locals del SERE, els seus llibres de comptabilitat registraven ingressos per valor de 100 milions de francs. Vegeu Abdón Mateos, La batalla de México: Final de la Guerra Civil y ayuda a los refugiados, 1939-1945 (Madrid: Alianza Editorial, 2009), 65, i Sánchez Asiaín, La financiación..., 1092.

20 Vegeu les cartes de Lluís Companys a Juan Negrín (27 de març de 1939 i 6 d’abril de 1939) i a Diego Martínez Barrios (12 d'abril de 1939), 7.5.1, Fons Generalitat de Catalunya a l'exili, ANC. I, també, la carta de Lluís Companys a Juan Negrín, datada a París el 27 de març de 1939, 7.5.1, doc. 1, ibídem.

21 Annex a la carta de Lluís Companys a Juan Negrín, datada a París el 6 d'abril de 1939, 7.5.2, doc. 4-6, ibídem. També és enviada a Diego Martínez Barrios el dia 12 d’abril de 1939, uns dies més tard, quan no es rep resposta de Negrín. Carta de Lluís Companys a Diego Martínez Barrios, 12 d'abril de 1939, 7.5.1, doc. 10-11, ibídem. 
control. El document posa de manifest que aquesta idea inicial havia estat rebutjada per les autoritats republicanes espanyoles i que Companys no defallí, això no obstant, a buscar una fórmula que respectés les particularitats de Catalunya i que evités la duplicació d'assignacions i d'ajudes. L'objectiu era, en definitiva, garantir «la persistencia con su peculiar perfil de los órganos políticos autónomos y la continuidad de la cultura catalana».

Per aconseguir-ho, va formular diverses propostes. La primera era que la Presidència de la Generalitat designés els seus representants dins el SERE, que concediria els auxilis als refugiats catalans en tots els aspectes pactats. Així, veiem com en una carta de Companys a Eduard Ragassol i a Jaume Aiguadé, escrita la tercera setmana del mes de març del 1939, els va demanar que acceptessin representar els seus interessos en l'organisme acabat de constituir el 2 d'abril de 1939.

M'han dit que aquesta Comissió (el SERE) està dividida en quatre seccions, una d'auxilis, altre de Refugiats, altre d'emigració i no sé quina més. Com en definitiva, la Junta executiva serà la que farà les coses, fora molt convenient que un dels representants catalans fos responsable d'alguna d'aquestes seccions, singularment, la de Refugiats. ${ }^{22}$

La segona era que el SERE atengués, dins el quadre econòmic general, les institucions i residències d'organització catalana, de manera que pogués controlar-ne el funcionament si calgués a fi i efecte d'assegurar que no es produïssin duplicitats en les assignacions. La tercera era que, dins el marc d'auxili general a favor de tots els republicans espanyols, el quadre d'auxili als refugiats catalans recollís recursos independents de la resta de funcions de la Comissió del SERE, que eren indispensables per a l'obra d'auxili catalana, això és, l'oficina d'informació per als refugiats catalans, que havia de vehicular les seves sollicituds d'ajuda al SERE; el centre de relació entre els diversos nuclis de catalans atesos pel SERE, que n’havia d'assegurar la unitat, i la continuïtat de la cultura catalana al marge dels ajuts genèrics del SERE a intellectuals republicans espanyols. Es tractava,

22 Cartes de Lluís Companys a Eduard Ragassol i a Jaume Aiguadé, datada a París el 7 d'abril de 1939, 7.5.1, doc. 4-8 i doc. 4-5, Fons Generalitat de Catalunya a l'exili, ANC. 
en definitiva, d'una colla de mesures orientades a reservar dins del SERE un volum de l'obra d'auxili per als refugiats catalans i de completar-la alhora per a aquells aspectes específicament autònoms amb una «obra complementaria de necesidades modestas». Companys hi apuntava que el model proposat era el mínim imprescindible per conservar la figura de la concepció autònoma de l'Estat republicà i que oposar-s'hi suposaria una voluntat expressa d'ofegar a l'estranger l'autonomia, la llengua, la cultura i l'esperit de Catalunya. A la Presidència de la Generalitat, com a primera magistratura de Catalunya, li'n correspondria l'organització.

La realitat és que les forces catalanistes republicanes no van tenir cap altra sortida que acceptar les regles del joc tal com els venien donades per sobreviure durant aquells primers mesos i que Negrín va dur a terme una política de fets consumats, que, tot i no evitar nombroses discussions, va garantir que no es revoqués la seva visió dels fets, segons la qual la Generalitat de Catalunya no existia com a figura jurídica a l'estranger, de manera que només els partits que hi havien tingut representació podien representar els exiliats catalans dins dels organismes d'auxili. ${ }^{23}$ Sembla que la intenció de Companys de disposar de recursos propis suficients que permetessin fomentar la unitat, a fi de sostenir econòmicament els exiliats de perfil polític afí, d'incentivar la cultura catalana i alhora de mantenir el control de la informació mediatitzant la connexió entre els refugiats catalans i el SERE, va ser boicotejada des del primer moment.

Després de la subvenció de 150.000 francs que la Generalitat havia rebut les primeres setmanes de l'exili per sostenir-se, i de la qual no s'ha trobat cap rastre administratiu o comptable, no va percebre cap altra assignació del Govern espanyol. ${ }^{24}$ Arran d'això, l'11 de març de 1939 la Generalitat es va veure obligada a tancar els comptes, de manera provisional, per manca de recursos. Encara el 12 de maig de 1939 Companys escriu al president de la Ponència Ministerial, organisme que controlava el SERE, queixant-se perquè no havia rebut cap altra quantitat de diners. Tot i les reiterades sollicituds d'ajuda per sostenir l'oficina de Presidència, els membres del

23 Carta de Lluís Companys a Juan Negrín, datada a París el 6 d’abril de 1939, 7.5.1, doc. 2-3, ibídem.

24 «Como prenda de una futura ayuda recibió el Gobierno de Cataluña del de la República, el día 2 de febrero próximo pasado, una subvención de ciento cincuenta mil francos», carta de Lluís Companys al president de la JARE, 17 d'agost de 1939, Co335Eoo1Coo3, AMTM. 
Govern i del Parlament de Catalunya, les residències i les institucions culturals, i per auxiliar la massa de refugiats, no es van materialitzar en els termes demandats. ${ }^{25}$

L'estira-i-arronsa entre la Generalitat de Catalunya i el SERE es va aturar amb un principi d'acord que es va posar de manifest el mes de juliol del 1939, quan es van començar a percebre els primers recursos segons els termes pactats. La primera subvenció formal respon als informes econòmics presentats per Antoni M. Sbert, per encàrrec de Companys, al SERE el 15 de maig de $1939 .{ }^{26}$ En aquest pressupost se sollicitaven 625.000 francs. El 2 de juliol de 1939 només se n'havien fet efectius 80.0oo, que es van pagar directament a la delegació de Perpinyà (CEuvre d'Entraide aux Républicains Catalans, OERC) per sostenir el servei de restaurant i que no consten en les liquidacions analitzades. Així doncs, a principis de juliol encara quedava que el SERE fes efectius 545.000 francs, que els catalans demanaven des de feia dos mesos però no acabaven de rebre mai. La primera transferència del SERE, entregada directament al president de la Generalitat, va ser de 207.640 francs al juliol. La dinàmica, doncs, sembla que és la següent: el SERE transferia diners que cobrien sempre una mica menys del pactat $i$, per descomptat, no feia mai efectiu l'import que permetés liquidar definitivament els deutes contrets des del març fins al juny del 1939, reclamats amb insistència, de manera que les finances catalanes fossin sempre un malviure ple d'estretors i de patiments. A la taula 1 s'hi relacionen els imports transferits pel SERE a la Presidència de la Generalitat per sostenir les institucions catalanes durant els mesos de juliol a setembre del $1939 .{ }^{27}$

25 Carta de Lluís Companys al president de la Ponència Ministerial (SERE), 12 de maig de 1939, 7.5.2, doc. 1-3, Fons Generalitat de Catalunya a l'exili, ANC; carta de Lluís Companys a Josep Moix, datada a París el 15 de juny de 1939, 7.5.1, doc. 12, ibídem; Annex, Subsidios mensuales pendientes de aprobación [llista], 26 de juliol de 1939, 22.5.1, doc. 2-3, ibídem.

26 Carta d’Antoni M. Sbert a Lluís Companys, 2 de juliol de 1939, 5.12.3, doc. 2, ibídem.

27 Extracte de la liquidació de caixa dels serveis d'assistència catalana administrats per la Fundació Ramon Llull, datada el 30 de setembre de 1939, 18.7.1, doc. 2, ibídem. El primer import de 207.640 francs pràcticament coincideix amb el que Companys va reconèixer haver rebut del SERE en la seva carta dirigida a la JARE del 17 d'agost de 1939, doc. Co335Eoo1Coo3, AMTM. 
Taula 1. Subvencions del SERE a la Presidència de la Generalitat

\begin{tabular}{ll}
1939 & Francs \\
\hline Juliol & $207.640,00$ \\
\hline Agost & $217.966,65$ \\
\hline Setembre & $250.000,00$ \\
\hline Total & $675.606,65$ \\
\hline
\end{tabular}

Font. 18.7.1, doc. 2, fons Artea, ANC

Així, doncs, es va portar endavant l'estratègia basada en l'escanyament. Malgrat que les necessitats de la Generalitat de Catalunya a l'exili rondaven els 450.000 francs mensuals de despesa, el SERE n'aportava la meitat. Aquests comptes no preveien partides ni per a l'oficina de Presidència, ni per als diputats catalans, ni per al Govern autònom, ni tan sols per a l'activitat cultural de la Fundació Ramon Llull, sinó que es van destinar gairebé íntegrament a refugis: principalment, el de Montpeller, però també a la delegació de Perpinyà destinada als refugiats internats als camps, amb una partida molt petita. Segons indiquen els documents, doncs, sembla que Negrín va estar d'acord a dedicar alguns recursos a sostenir residències i donar suport a la tasca assistencial que es feia des de Perpinyà, però no a finançar ni els representants polítics de la Generalitat ni les institucions que representaven. En total, el SERE va transferir directament al president de la Generalitat un total de 825.606,65 francs ( 150.000 francs inicials més la suma de les tres aportacions contingudes a la taula 1) per ajudar-lo a dur a terme el projecte polític presentat a començaments d'abril del 1939 (sense comptar-hi els esmentats 80.000 francs aportats directament per pagar el servei de restaurant de Perpinyà). Aquesta quantitat periodificada entre els mesos d'abril i de setembre del 1939 dona una aportació mensual mitjana de 137.601 francs, cosa que va fer d'aquest període una travessa pel desert força dura, més encara si es considera que els catalans eren a l'exili des de començaments de febrer. 
El govern basc a l'exili, per contra, va arribar a l'abril a un acord amb el SERE molt beneficiós d'aproximadament dos milions de francs al mes. ${ }^{28}$ La taula 2 ens ajuda a comprendre la dimensió de l'acord econòmic a què es va arribar i a entendre la diferència respecte al cas català. Sabem que en el pla teòric els membres del PNB, juntament amb el lehendakari Aguirre, van acordar una política teòrica de no collaboració amb el Govern de la República, però a la pràctica el president basc va establir llaços primer amb Negrín i, des del mes de desembre del 1939, amb Prieto per assegurar un finançament que permetés l'assistència als refugiats bascos i el sosteniment de les institucions a l'exili. Com ens recorda Ludger Mees en la seva biografia d’Antonio Aguirre, el conflicte del 1939-1940 el va resoldre el president basc mercès a la seva habilitat política, però també a la unitat prou harmònica que hi havia entre els polítics nacionalistes bascos, que eren respectats pels seus militants de base. Tot plegat va facultar-lo per negociar amb força i amb les espatlles cobertes. ${ }^{29}$

28 Acord del SERE amb el Govern basc, signat per Francisco Menéndez Aspe el 26 d'abril de 1939, Co35oEoo1Doo3, AMTM.

29 Ludger Mees, El profeta pragmático (Irún: Alberdania, 2006), 23-32. 
Taula 2. Resum de despeses del Govern d'Euskadi finançades pel SERE (març 1939 - maig 1940) en francs ${ }^{30}$

\begin{tabular}{|c|c|c|c|c|c|c|c|}
\hline & $\begin{array}{c}\text { Març } \\
1939\end{array}$ & $\begin{array}{l}A b r . \\
1939\end{array}$ & $\begin{array}{c}\text { Maig } \\
1939\end{array}$ & $\begin{array}{l}\text { Juny } \\
1939^{*}\end{array}$ & $\begin{array}{c}\text { Jul. } \\
1939^{*}\end{array}$ & $\begin{array}{c}A g . \\
1939\end{array}$ & $\begin{array}{c}\text { Set. } \\
1939\end{array}$ \\
\hline $\begin{array}{l}\text { Total despeses } \\
\text { reals }\end{array}$ & - & - & 2.109 .515 & 2.283 .344 & 2.108 .640 & - & - \\
\hline Emigració & - & - & - & - & - & - & - \\
\hline Delegacions & - & - & - & - & - & - & - \\
\hline Refugis & 829.000 & - & - & 852.000 & 863.605 & 858.500 & 823.000 \\
\hline Camps & 500.000 & - & - & 500.000 & & & \\
\hline Subsidis & 535.600 & - & - & 580.000 & 589.395 & 601.500 & 559.500 \\
\hline Socors & 50.000 & - & - & 45.000 & 126.000 & 141.000 & 80.000 \\
\hline $\begin{array}{l}\text { Despeses } \\
\text { generals }\end{array}$ & & - & - & & & & \\
\hline $\begin{array}{l}\text { Mutilats, ass. } \\
\text { sanit. / escolar }\end{array}$ & 544.500 & - & - & 478.000 & 606.000 & 730.000 & 650.000 \\
\hline $\begin{array}{l}\text { Total } \\
\text { pressupost }\end{array}$ & 2.459 .100 & - & - & \multicolumn{4}{|c|}{2.455 .0002 .185 .0002 .331 .0002 .112 .500} \\
\hline
\end{tabular}

$30 \mathrm{El}$ quadre ha estat elaborat utilitzant les fonts següents, provinents de l'AMTM, que es consignen a continuació esmentant primer el títol o el concepte del document seguit, entre parèntesi, del codi d'arxiu: Pressupostos bascos, SERE, ag. 1939 (Co349E001Co01); Pressupostos bascos d'assistència social, març 1939 (Co350Eoo1Doo1); Pressupostos bascos, SERE, juny 1939 (Co35oEoo1Doo5); Intervenció del SERE en refugis bascos (Co35oEo01Doo6); Pressupostos bascos d'assistència social, juny 1939 (Co35oEoo1Doo7); Resum de despeses d'assistència als bascos, maig-jul. 1939 (Co350Eoo1Doo); Despeses bascos vs. pressupostos, jul. 1939 (Co350Eoo1Do10); Despeses: bascos, jul. 1939 vs. juny 1939 (Co35oEoo1Do11); Pressupostos bascos, ag. 1939 (Co350Eo01Do12); Pressupostos bascos, ag. 1939 (Co35oEoo1Do13); Pressupostos bascos, set. 1939 (Co35oEoo1Do14); Pressupostos bascos, oct. 1939 (Co350Eo01Do15); Resum de despeses: bascos, feb.-abr. 1940 (Co350Eoo1Do17); Resum de despeses: bascos, feb.-maig 1940 (Co350Eo01Do18); Pressupostos: bascs, detall (oct. 1939) (Co350E001Do19). 
Oct. Nov. Des. Gen. Febr. - Abr. Maig 1940 $\begin{array}{llllll}1939 & 1939 & 1939 & 1940 & \text { Març 1940 } 1940\end{array}$

\begin{tabular}{|c|c|c|c|c|c|c|c|}
\hline $\begin{array}{l}\text { Total despeses } \\
\text { reals }\end{array}$ & - & - & - & - & 8.680 .899 & 7.618 .269 & 1.651 .932 \\
\hline Emigració & - & - & - & - & 1.370 .583 & 3.357 .069 & 420.822 \\
\hline Delegacions & - & - & - & - & 815.000 & 120.000 & c \\
\hline Refugis & 592.000 & - & - & - & 623.956 & 307.870 & 163.291 \\
\hline Camps & - & - & - & - & 58.500 & 64.758 & 32.000 \\
\hline Subsidis & 643.000 & - & - & - & 4.103 .016 & 388.500 & 125.600 \\
\hline Socors & - & - & - & - & 31.996 & 43.519 & 86.633 \\
\hline $\begin{array}{l}\text { Despeses } \\
\text { generals }\end{array}$ & - & - & - & - & 1.228 .447 & 286.553 & 158.584 \\
\hline $\begin{array}{l}\text { Mutilats, ass. } \\
\text { sanit. / escolar }\end{array}$ & 509.000 & - & - & - & 449.400 & 3.050 .000 & 665.000 \\
\hline $\begin{array}{l}\text { Total } \\
\text { pressupost }\end{array}$ & 1.744 .000 & - & - & - & - & - & - \\
\hline
\end{tabular}

* Els mesos de juny i juliol del 1939 les xifres de detall són el pressupost i el total és el real. Font. Quadre d'elaboració pròpia amb documents de l’AMTM

Aquests recursos van permetre a Aguirre disposar de residències per a més de 2.500 persones, centres culturals, hospitals, consultoris, residències de mutilats i sanatoris, que en total sumaven mitja dotzena d'installacions d'assistència sanitària i una multitud d'iniciatives de tota mena. És lògic, per tant, que els bascos renunciessin amb contundència a l'oferta de nomenar Manuel Irujo secretari general de la Junta de Auxilio a los Republicanos Españoles (JARE), feta l'estiu del 1939 pel president d'aquest organisme. ${ }^{31}$ Les relacions entre la comunitat basca i els partidaris de Juan Negrín van ser cordials, i ell no va posar cap impediment perquè el Govern basc i les seves institucions sobrevisquessin a l'exili en unes condici-

31 Carta de Manuel de Irujo a Indalecio Prieto, en què refusa la incorporació del Govern basc a la JARE, de l'agost del 1939, Co335Eoo1Coo4, AMTM. 
ons molt dignes i de gran autonomia de gestió. Aquesta política de concentració d'elements polítics i intellectuals, comparable a la catalana, va ser respectada i sostinguda directament per les autoritats republicanes espanyoles amb generositat.

És possible que les tensions entre la Generalitat i el Govern central, gestades durant la Guerra Civil, expliquin que les autoritats republicanes, convençudes en bona mesura de la culpabilitat dels catalans en la derrota, volguessin cobrar-s'ho condemnant-los a un exili miserable. En totes les cartes del president Companys als membres de la Ponència Ministerial o a les dirigides al president de la JARE es va mostrar respectuós amb la qüestió basca, que qualificava de justa i de model per al cas català.

Al marge de la qüestió basca, els catalans continuaven intentant rebre el finançament que creien just per aconseguir una autonomia econòmica. La corda es va anar tensant fins al punt que el 8 d'agost de 1939 Companys envià una de les darreres cartes a Negrín, en què insistia de nou en la necessitat d'arribar a l'acord econòmic que tantes vegades s'havia demanat però que mai no s'havia materialitzat més que en la petita aportació del juliol, i l'advertia que si el 15 d'agost no rebia resposta del cap de l'Executiu espanyol «es veuria obligat a prendre la determinació que creuria més convenient als interessos de Catalunya».32 En efecte, la Generalitat havia anat gastant els diners que no tenia i acumulava nombrosos deutes: des del préstec inicial per endegar la Fundació Ramon Llull de 120.000 francs, fins a múltiples factures pendents fiades pels proveïdors de la residència d'exiliats de Montpeller, de la delegació de Perpinyà, etc.

Amb les aportacions tan migrades del SERE en relació amb les necessitats que calia sufragar, no és estrany que els catalanistes republicans sollicitessin l'ajuda de la Diputació Permanent de les Corts, que, des de la constitució de la JARE l'estiu del 1939 amb els fons provinents del iot Vita, era una bona alternativa a l'organisme impulsat per Negrín. ${ }^{33}$ En aquest estat de coses el president català va decidir l'estiu del 1939 demanar prioritàri-

32 Carta de Josep Tarradellas a Carles Pi i Sunyer, 21 d'agost de 1939, Cogo3Eoo1Coo6, AMTM.

33 Ernest Udina comenta en la seva biografia sobre Josep Tarradellas que sempre va ser un home clau de la JARE, a la vegada que va saber mantenir bones relacions amb Negrín. Vegeu Ernest Udina, Josep Tarradellas: L'aventura d'una fidelitat (Barcelona: Edicions 62, 1978), 225. 
ament recursos a la JARE, ${ }^{34}$ que, recentment constituïda, estava enfrontada al SERE, i exposar-li el deute, que era valorat en els termes següents:35

\section{Taula 3. Estat de comptes de la Generalitat (17 d'agost de 1939) presentat a la JARE}

CAPÍTULO I - Obligaciones contraídas Francos franceses

$1^{\text {o }}$ Créditos pendientes: Obligaciones contraídas desde el mes de Mayo hasta el 31 de Julio por gastos de sostenimiento de las residencias sostenidas y subvencionadas por la administración catalana 338.000

$2^{\circ}$ Parlamento de Cataluña: Subsidios que se acreditan los señores diputados que no los perciben por otros conceptos, desde el mes de Marzo

$3^{0}$ Residencias: Subvención prevista para el mes de Agosto 250.000

$4^{\circ} \quad$ Instituciones culturales: Subvención para el mes de Agosto 100.000

$5^{\circ}$ Presidencia de la Generalidad: Atenciones de Secretaría, habilitación y oficina

Podem interpretar aquest quadre com un intent d'aconseguir una subvenció més elevada exagerant les despeses que calia cobrir a fi de resoldre de cop tots els problemes financers de la Generalitat a l'exili, atès que la política d'escanyament del SERE, que li donava uns 250.000 francs al mes, només li permetia de sostenir una residència per a exiliats, la de Montpeller, però ni deixava marge per a activitats culturals de certa volada ni permetia de projectar que els membres del darrer Govern català, del Parlament o el mateix president tinguessin subvencions més enllà de les que poguessin percebre per haver desenvolupat càrrecs al Govern de la República o a alguna de les seves institucions al marge de la Generalitat, cosa que altrament no hauria d'estranyar-nos. El govern Negrín, dominat pels

34 Lluís Nicolau d'Olwer, president, i Josep Andreu Abelló, vocal, foren peces importants i homes de confiança del catalanisme en el si de l'organisme. Vegeu Joan Esculies, Josep Andreu Abelló: Els clarobscurs del catalanisme (Barcelona: Edicions de 1984, 2015), 192-194.

35 Carta de Lluís Companys a la JARE, 17 d'agost de 1939, Co335Eoo1Coo3, AMTM. 
comunistes, havia considerat, ja en els darrers dies de la Guerra Civil, que la Generalitat i les seves institucions havien estat una de les causes de la pèrdua de la contesa. Van ser constants els estirabots dels comunistes, que titllaven els catalanistes de derrotistes i mancats d'esperit de collaboració amb l'esforç de guerra. Així, el darrer moviment centralista es va portar a terme a l'exili, cosa que va dur la Generalitat a la fallida, a la inoperància i al descrèdit davant dels seus correligionaris, com a mínim durant els seus primers sis mesos d'exili, certament els més difícils.

Francisco Gracia i Gloria Munilla, en l'últim monogràfic dedicat a dilucidar els recursos de què va disposar la JARE, recullen la peripècia del iot noliejat per Negrín i els valoren en uns 5.250.00o dòlars americans (d'ara endavant, "dòlars"), és a dir, a l'entorn d'uns 200 milions de francs: la quantitat invertida per la JARE entre la seva constitució i el tancament de les oficines franceses al maig del 1940 ascendia a 20 milions de francs. ${ }^{36}$ Com va afectar aquest moviment polític i de recursos a les finances de la Generalitat de Catalunya? En paraules del mateix Companys en una carta al president de la JARE, la seva posició a mitjan agost era la següent:

La Diputación Permanente de las Cortes acordó la constitución de la Junta (JARE) de su digna Presidencia [...]. La representación parlamentaria de los republicanos catalanes, fiel a la legitimidad y solidaria con los principios morales que informan la constitución de ese alto organismo administrativo, no vaciló en darle su colaboración. ${ }^{37}$

Aquesta collaboració era bastant ambigua, perquè quan el president escrivia aquesta missiva encara estava jugant les dues cartes alhora, atès

36 Gracia \& Munilla, El tesoro del 'Vita'... Les quantitats difereixen entre els 5.303.281,49 dòlars provinents de la comptabilitat de la JARE i els 5.285.28o,47 provinents de l'estudi de la liquidació forçada pel Govern mexicà el desembre del 1942; ibídem, 312. Hem de tenir en compte, però, que els béns del Vita no es van convertir en diner efectiu fins al començament del 1940, ibídem, 119. Altres autors com José María Del Valle, citant Juan Negrín, comenten que inicialment comptava amb uns 250 milions de francs del 1939. Altrament, Abdón Mateos s'inclina per uns 10 milions de dòlars (uns 376 milions de francs del 1939). A partir d'aquestes dades, que extreu del llibre d'actes reservat de la JARE i conservat al Fons Carlos Esplà, afirma que coincideixen amb el balanç realitzat per les autoritats mexicanes quan van intervenir l'organisme durant els anys 1942 i 1943. Del Valle, Las instituciones de la República..., 33, i Abdón Mateos, La batalla de México..., 119.

37 Carta de Lluís Companys al president de la JARE, 17 d'agost de 1939, Co335Eoo1Coo3, AMTM. 
que el trencament definitiu amb el SERE encara no s'havia consumat. Les trameses de diners de l'organisme controlat per Negrín van arribar, com sabem, a finals d'agost (217.966 francs) i al setembre (250.00o francs), absolutament solapades amb els nous ingressos que havien començat a arribar de la JARE. A la mateixa carta li exposa les necessitats de fons mensuals mínimes en els termes següents:

\section{Taula 4. Estat de comptes de la Generalitat (17 d'agost del 1939) presentat a la JARE}

\section{CAPÍTULO II - Subvención mensual}

$1^{\circ} \quad$ Parlamento de Cataluña: Para la mesa y señores diputados del Parlamento Catalán que no perciben subsidio por otros conceptos 75.000

$2^{\circ}$ Residencias: Subvención para contribuir a su sostenimiento 250.000

$3^{\circ}$ Instituciones culturales: Subvención mensual 100.000

$4^{\circ}$ Presidencia de la Generalidad: Subsidio para el Presidente y miembros del último Gobierno, gastos de Secretaría y habilitación y atenciones diversas

Afortunadament per a la Generalitat, aquesta proposta fou acceptada, com s'acceptà també el pagament del deute endarrerit. En poc més de quinze dies, es feren efectius pagaments per valor d'1.138.0oo de francs ${ }^{38} \mathrm{i}$ la subvenció sollicitada per al mes de setembre del 1939 de 500.000 francs. 39 Des de llavors i durant els mesos següents, com a mínim fins a la caiguda de França la primavera següent, no ens consta que el pacte es trenqués ni que deixessin de rebre's els fluxos promesos de manera regular. Per fer-se

38 «De moment, tinc la satisfacció de dir-vos que avui ja hem cobrat mig milió de francs a compte; quant a la resta, em sembla que abans del fi de setmana serà pagat», carta de Josep Tarradellas a Carles Pi i Sunyer, 21 d'agost de 1939, Co9o3Eoo1Coo6, AMTM.

39 «Us he d'informar que justament avui hem cobrat de la JARE la resta de la quantitat demanada, o sigui 638.000 francs. A més la JARE accepta de concedir-nos una subvenció mensual de mig milió de francs i, per tant, queda resolt el problema de les residències, Fundació, Diputats, etc. Ja veieu, doncs, que una vegada que l'Esquerra fa la seva política, obtenim un èxit», carta de Josep Tarradellas a Carles Pi i Sunyer, 28 d'agost de 1939, Cogo3Eoo1Coo8, AMTM. 
una idea clara de quants diners rebé l'oficina de Presidència a França entre el febrer i el setembre del 1939 de mans de les institucions republicanes a l'exili, d'un o altre signe, podem dir que en total foren aproximadament 2.463.606,65 francs, és a dir, una mitjana de 307.950,83 francs al mes.

\section{Organització administrativa i institucional}

Amb l'anàlisi dels pocs documents econòmics conservats, ${ }^{40} \mathrm{com}$ hem vist, coneixem els recursos amb què comptaven i d'on els obtenien, però també ens donen una idea de com s'organitzaven administrativament. ${ }^{41}$ Sembla prou contrastat perquè puguem distingir, més o menys nítidament, tres fases en l'evolució de les competències i de les responsabilitats dins les activitats portades a terme per la Generalitat durant aquest període en territori francès, que podríem resumir en l'esquema següent:

40 a) Comptes d'explotació i resums de despeses dels serveis d'assistència catalana. Cartes enviades per Antoni M. Sbert a Lluís Companys, 2 de juliol de 1939, 2 d'agost de 1939 i 15 d'agost de 1939, 5.12.3, doc. 1-11, Fons Generalitat de Catalunya a l'exili, ANC. $b$ ) Relació de despeses, per conceptes, de la Fundació Ramon Llull durant els mesos d'agost, setembre i octubre del 1939, 7.2.6, íbídem. 2. c) Resum dels pagaments dels serveis d'assistència catalana corresponent al mes de desembre del 1939, 3.1.1, ibídem. d) Ingressos i despeses del Comité d'Aide aux Intellectuels Catalans, agost del 1938 - març del 1939, 5.8.2, doc. 1-26, ibídem. e) Resum de despeses i compte d'explotació del Comité d'Aide aux Intellectuels d'Espagne, del 15 de març de 1939 al 25 de setembre de 1939, 25.3.1, doc. 7 i 5.8 .4 i doc. 8, ibídem. f) Despeses dels serveis d'assistència de l'CEuvre d'Entr'Aide aux Républicains Catalans a Perpinyà, del març al desembre de 1939, 24.1.3 i 7.4.2, ibídem.

41 Fins al moment, els únics documents econòmics publicats relatius a les activitats de l'oficina de Presidència (en aquest cas, la Fundació Ramon Llull) són $a$ ) els que s’han trobat entre els papers donats per la família Pi i Sunyer i que havien estat conservats per l'exconseller de Cultura i $b$ ) la memòria d'activitats escrita per Antoni M. Sbert el 1939, que va ser publicada per Josep Massot i Muntaner, Antoni M. Sbert: Agitador, polític i promotor cultural (Barcelona: Publicacions de l'Abadia de Montserrat, 2000). 
Figura 1. Evolució dels organismes d’assistència, febrer 1939 - juny 1940

Febrer - juny 1939

\section{Oficina de Presidència}

Sota el paraigües de la Fundació Ramon Llull · Control d'assistència, informació, cultura i residències

Juny - octubre 1939: Creació del Bureau d’Information

\section{Bureau d'Information}

c. Monceau, 16

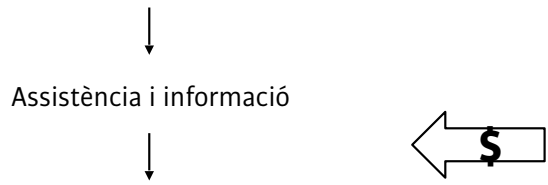

Carles Martí Feced

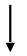

OERC Perpinyà
Fundació Ramon Llull

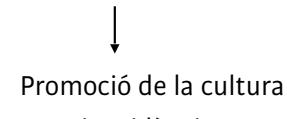

i residències

L. Companys, J. Tarradellas,

Octubre 1939 - juny 1940: Dissolució del BI, separació de competències: cultura i residències

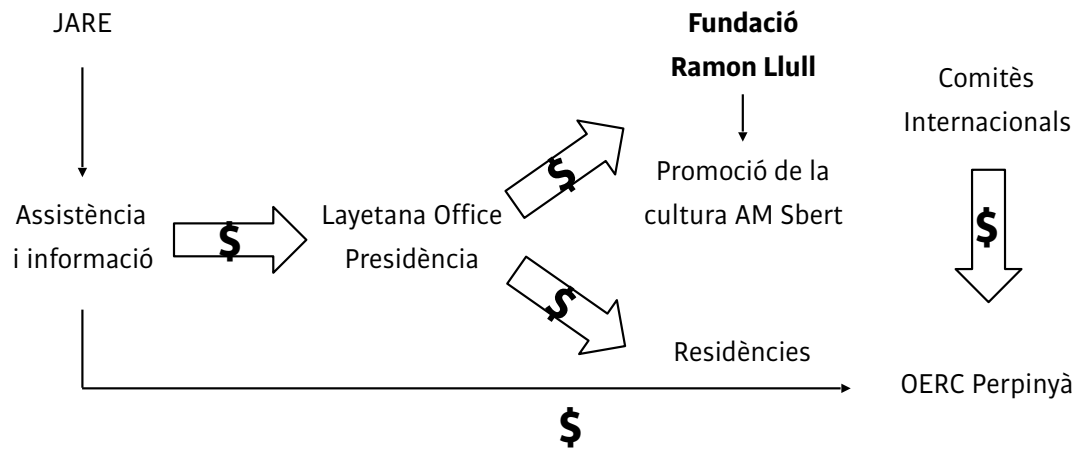

En la primera fase, que va des del mes de febrer fins al mes de juny del 1939, totes les activitats d'assistència i d'informació, de cultura i de residències van dependre de l'oficina de Presidència sota l'empara de dife- 
rents organismes previs a la constitució legal de la Fundació Ramon Llull com a tal. ${ }^{42}$ Durant aquest període, es va operar a través del Comité de Patronage des CEuvres Culturelles et d'Assistance Catalanes, acabat de crear dins la secció catalana de l'Association des Amis de la République Française. Un cop superada aquesta primera fase i amb tots els obstacles jurídics remoguts, l'estiu del 1939 es va constituir, d'acord amb la llei francesa d'associacions del 1901, la Société des Amis de la Fondation Ramon Llull, amb domicili al número 81 del carrer Miromesnil, al bell mig de París. La segona fase, a partir del mes de juliol del mateix any, comença amb la creació del Bureau d'Information, ${ }^{43}$ al número 16 del carrer Monceau a París, encarregat de les tasques d'assistència i d'informació, mentre que la gestió de les residències i la promoció de la cultura van continuar en mans de la Fundació, presidida per Antoni M. Sbert. Finalment, en la tercera fase, iniciada el mes d'octubre del 1939 i que va durar fins al juny del 1940, la Fundació Ramon Llull només es va dedicar al suport de la cultura i de la llengua, mentre que l'oficina de Presidència, anomenada Layetana Office, es va dedicar de ple a les residències. ${ }^{44}$ L'assistència social i la informació es va deixar, majoritàriament, en mans de la JARE a través de representants catalans al seu si, la qual cosa va suposar el tancament del Bureau d'Information.

Els homes de la Generalitat, durant els setze mesos que la Fundació Ramon Llull va ser a París, van ocupar un total de cinc immobles diferents, com es pot apreciar a la taula següent:

42 Antoni Maria Sbert, «Memòria de la Fundació Ramon Llull», Revista de Catalunya [Mèxic] (gen. 1940): 99-101, reproduit dins Massot i Muntaner, Antoni M. Sbert..., 291-321. Altres fonts ho entendrien a l'inrevés, és a dir, que primer es crearia la Fundació Ramon Llull i després la Société des Amis de la Fondation Ramon Llull i el Comité de Patronage des CEuvres Culturelles et d'Assistance Catalanes, constituït entre el juny i l'agost del 1939 dins la secció catalana de l'Association des Amis de la République Française. Vegeu Esculies, Josep Andreu Abelló.., 181.

43 Disposicions que regulen l'actuació de les oficines del número 16 del carrer Monceau, 1 de juny de 1939, doc. Co350Eoo1Doo, AMTM.

44 Carta de Layetana Office a Pere Mias, 10 d'abril de 1940, 7.2.1, doc. 197, Fons Generalitat de Catalunya a l'exili, ANC. 
Figura 2. Esquema general d'institucions d'assistència a catalanistes republicans al primer exili

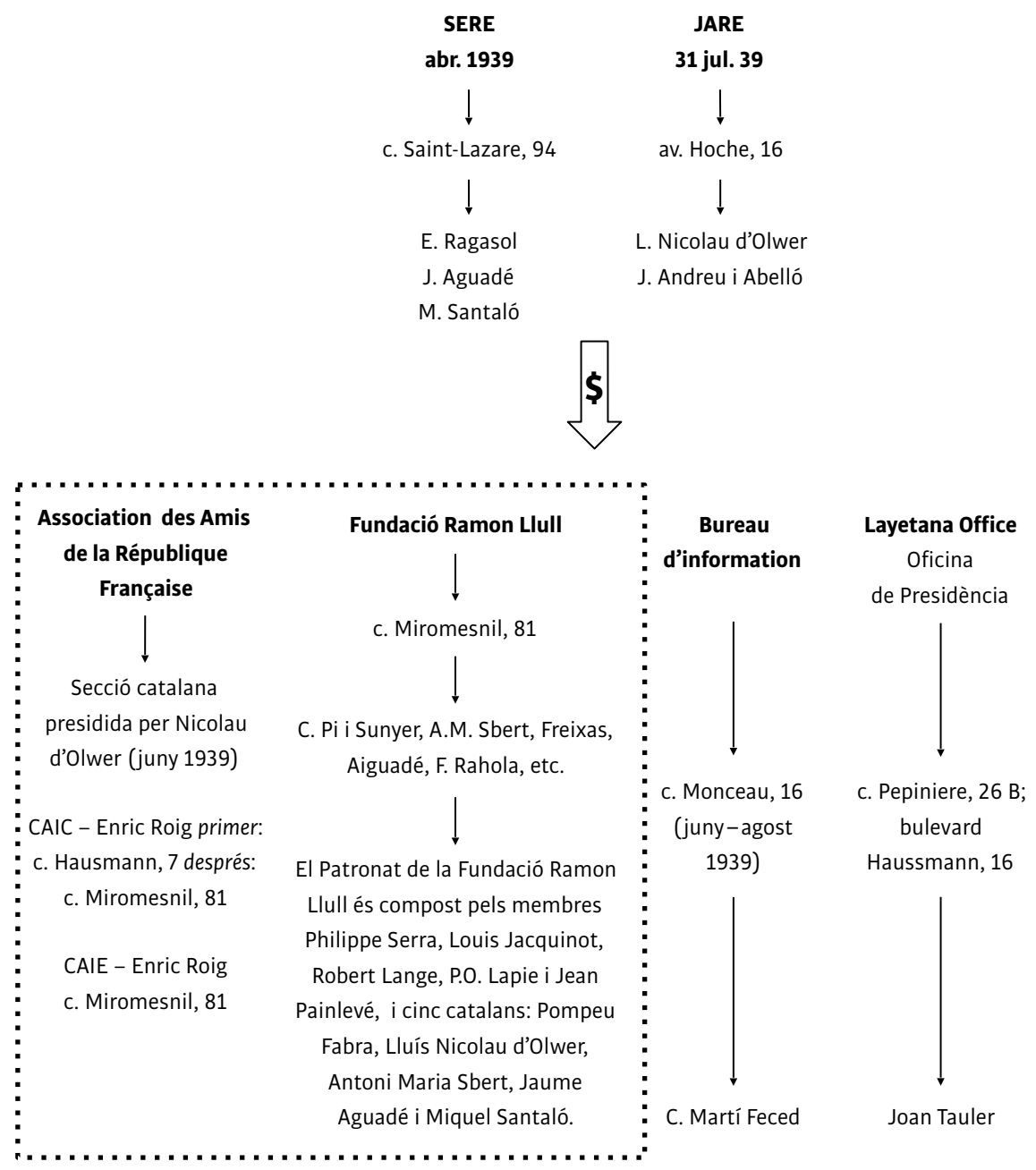

Les oficines dels diferents organismes es van emplaçar al número 81 del carrer Miromesnil, al número 7 i 16 del bulevard Haussmann, al número 16 del carrer Monceau, i al número 26 del carrer Pépinière. Tots eren en un dels millors barris de la capital francesa (els districtes 8 i 9 de París) i es trobaven, doncs, relativament a prop entre ells i no gaire lluny dels lo- 
cals ocupats pel SERE i per la JARE. També es va installar una oficina de la Generalitat a Perpinyà, que feia de connexió amb els camps d'internament i de la qual parlarem més endavant. En alguns casos es poden determinar amb exactitud els períodes d'ocupació de les diferents oficines i qui hi treballava, si bé en la majoria de casos no és tan clar, perquè hi havia diversos ens jurídics domiciliats alhora en una mateixa oficina. Alguns, a més, van canviar de seu amb el transcurs dels mesos o les van abandonar definitivament quan els convenia per raons polítiques.

Si s'observa l'estat de la qüestió a partir dels documents sobre l'oficina de Presidència — la més important de totes—, sembla que els mesos de juliol i agost del 1939 hi havia una administració central formada per Enric Roig com a cap, Joan Tauler com a habilitat o apoderat per la Presidència davant del SERE i de la majoria dels bancs, un adjunt i un secretari. Aquests treballadors rebien remuneracions suficients per viure dignament; és a dir, era un equip d'administració petit però molt ben pagat. ${ }^{45}$ Aquest conjunt d'oficines intentaven coordinar, com hem vist, tasques d'informació, d'atenció als exiliats catalans, d'administració dels recursos i de foment de la cultura en major o menor grau.

L'acord de finançament amb la JARE, amb la situació econòmica aparentment resolta, va marcar un abans i un després en l'organització administrativa catalana. Josep Tarradellas va explicar a Carles Pi i Sunyer en una carta del 21 d'agost de 1939 com havia decidit tancar les oficines d'atenció als refugiats del Bureau d'Information, tot just inaugurades dos mesos abans, i clausurar la delegació de Perpinyà. En aquesta carta es comenta que els dos organismes eren de factura política i no només d'atenció humanitària, percepció que distava de ser compartida per les persones que en formaven part, com ara Ramon Frontera, un cas que veurem més endavant. Per Josep Tarradellas, la comesa de l'oficina de Perpinyà «era la de rebre la gent que contínuament passava la frontera i passava notícies de Catalunya. És a dir, el llaç d'unió entre una frontera i l'altra».46 Com que en aquells moments l'oficina del SERE a Perpinyà es va passar a la JARE en bloc, alguns dels homes d'ERC i d'ACR van aprofitar l'ocasió

45 Entre 2.000 i 3.500 francs per persona i mes.

46 Carta de Josep Tarradellas a Carles Pi i Sunyer, 21 d'agost de 1939, Cogo3Eoo1Coo6, AMTM. 
per incorporar-s'hi. Continua la carta referint-se al Bureau d'Information del carrer Monceau i assegura que «era també necessari tancar-lo», en paraules de l'exconseller, «car malgrat propagar constantment la veritat, és a dir, que no tenien diners, que feien tots plegats un sacrifici per mantenir-lo, ningú no s'ho creia, tothom pensava el contrari, continuava la crítica, la difamació i no era possible humanament continuar mantenint-se en aquella lluita contra els qui mai havien fet res, ni feien, però que llur crítica constant arribava a fer creure als altres que tenien raó, ja que d'una manera cínica especulaven en les misèries i dolors dels catalans que es trobaven a l'exili».47 De llavors en endavant, l'atenció als refugiats catalanistes es va haver de fer a les oficines de la JARE. Des d'un petit despatx van treballar per als refugiats Josep Andreu Abelló — que va ser vocal de la institució prietista i que el setembre del 1939 va marxar a Mèxic-, Frederic Rahola com a secretari particular i una mecanògrafa, la identitat de la qual desconeixem.

A partir de la tardor del 1939 es va fomentar la presència de representants catalans als organismes d'ajuda promoguts per les autoritats republicanes més que no pas l'engreix d'una burocràcia de perfil propi..$^{4} \mathrm{Amb}$ aquests moviments, la Generalitat va renunciar al control directe de les eines d'informació i va debilitar la seva xarxa clientelar, cosa que va evitar també el propi desgast davant els militants de base. Les crítiques i la manca de recursos van ser les principals raons per les quals la Generalitat va cedir completament la tasca assistencial de base i va perdre, també, l'ascendent sobre els refugiats afins políticament així com gran part de la seva capacitat d'influència.

\section{Política d’assignació de recursos al primer exili}

Com hem vist, la Generalitat disposava d'alguns recursos, encara que fossin migrats, tant d'ordre administratiu, que la dotava de capacitat per im-

47 Ibídem.

48 «Totes les coses que facin referència a exiliats, aniran, unes a l'oficina de l'Andreu al JARE i les altres a la Secretaria de l'Aguadé al SERE [...]. D’aquesta manera espero que podrem atendre a tothom, estalviarem el 80 per 100 de la nòmina actual i s'hauran acabat les crítiques sobre l'Esquerra, car aquesta ja no tindrà oficines ni funcionaris», ibídem. 
pulsar iniciatives, com d'ordre efectiu, que li permetia materialitzar-les. Analitzant alguns documents, com pressupostos o resums de despeses i comptes d'explotació diversos, podem fer-nos la idea de les prioritats a l'hora de fixar els criteris de despesa, que seguiren, com és lògic, un objectiu polític marcat prèviament. Aquestes línies d'acció es reduïren sobretot a tres àrees, que analitzarem per separat: atenció a polítics i administració, foment i protecció de la cultura, i cobertura assistencial als refugiats de base.

\section{Residències i polítics: tots els homes del president}

En tots els comptes la partida més rellevant va ser sempre la de les dues residències sota control propi: Montpeller i Isle-Adam/Boissy-la-Rivière, que costaven mensualment uns 250.000 francs, quantitat considerable per a l'època i per al moment. Aquestes despeses inclö̈en l'allotjament (lloguers, subministraments, material de neteja), manutenció, ${ }^{49}$ despeses d'administració ${ }^{50}$ i despeses relatives a roba i vestuari (reposició de roba i calçat, material per a costura, bugaderia i roba de casa, etc.). ${ }^{51}$ Aquestes residències hostatjaren quadres polítics com ara alcaldes, regidors i membres destacats dels partits catalanistes, així com escriptors, pensadors, intellectuals i artistes de perfils diversos. En total es tractava d'un collectiu permanent d'unes 250 persones a què, al llarg d'aquells mesos, se sumarien de manera itinerant un grup format per entre 600 i 800 refugiats. El fet que les despeses de la residència de Montpeller fossin assumides majoritàriament per la Generalitat — encara que no participés de manera exclusiva en el projecte - va determinar que en tingués un control gairebé total..$^{52}$ No només això, el fet que es volgués destinar a aquest equipament

49 La manutenció incloïa 10,50 francs per persona i dia. Per fer-nos una idea de les dimensions, el pressupost del mes d'agost del 1939 preveia 9.000 estades de 10 francs per persona i dia, és a dir, 300 persones. Efectivament, es van pagar 7.852 estades de 10 francs per persona i dia, això és, 262 persones, que és la xifra d'estadants d'aquell mes que sembla plausible.

50 Manuel Alcàntara en va ser l'administrador en cap.

51 En el cas de la residència per a intellectuals Isle-Adam/Boissy-la-Rivière també s'inclou una partida per pagar el servei domèstic.

52 «Je suis rentré a París le 23, aprés avoir arreté a Montpellier pour m’entretenir avec le Comité et les amis que nous aident, tout particularment avec Mr. Amade. Nous tractons [sic] de formaliser a 
el $83 \%$ dels fons de la Generalitat de Catalunya a França corresponents al mes de juliol del 1939 (això és, 212.250 francs) va marcar i determinar enormement les seves prioritats per sobre d'altres necessitats que calia cobrir. Amb la mateixa idea, a pocs quilòmetres al sud de París la Generalitat va installar, també amb l'ajut d'amics francesos, una petita residència en un molí propietat de Marc Sagnier, a la localitat de Boissy-la-Rivière. ${ }^{53}$ Aquest alberg també depenia econòmicament de l'oficina de Presidència i, per haver allotjat algunes personalitats del món literari català, com el mateix Carles Riba, ja ha estat investigat per diversos autors. ${ }^{54}$ L'anàlisi del seu pes econòmic (22.300 francs al mes, un 8,7 \% del total de despeses) ens reafirma en la idea que va ser una iniciativa exclusivista i d'abast limitat, reduïda a un conjunt realment petit i escollit de catalans intellectualment prominents. La protecció d'aquest petit grup de persones és el que considerem el pla principal, que coincideix amb algunes de les línies que va marcar Carles Pi i Sunyer poc temps després de creuar la frontera: «Agrupar els nuclis de catalans exiliats responsables i persones representatives en una organització conjunta [...]. Creació de residències o allotjaments per a grups de refugiats en centres urbans».55

Seguint l'anàlisi dels comptes també trobem una partida menor i d'aparença de calaix de sastre anomenada «subvencions del mes a residències

Montpellier une organisation pareille à la votre, pour les catalans, avec un centre d'haubergement», carta d'Antoni M. Sbert al Dr. Camile Soula, 26 de febrer de 1939, Fons Maria Baldó $5 S_{420}$, Arxiu Municipal de Tolosa de Llenguadoc.

53 Precisament el mes de juliol es traslladà a la també veïna Isle-Adam, situada al nord de la capital francesa. «En aquest antic molí coincidiren els Soldevila, Carles Riba i Clementina Arderiu amb tres fills, Josep M. Capdevila (que ben aviat marxà a Colòmbia), el pintor Ignasi Mallol i la seva família, i Manuel Pijoan, antic secretari del conseller de Cultura de la Generalitat, Antoni M. Sbert. Poc després s'hi afegiren les famílies de Pau Romeva i del pintor Joaquim Sunyer. Bona part d'aquest grup — bàsicament els Soldevila, els Riba, els Romeva i els Sunyer, als quals s'afegí la família de l'escultor Joan Rebull— es traslladà, a primers de juliol del 1939, a Isle-Adam», Ferran Soldevila, Dietaris de l'exili i del retorn, vol. 1, L'exili (València: Eliseu Climent, 1995), 13.

54 «En un poblet prop d’Étampes, En J. M. Capdevila, En F. Soldevila, el pintor Mallol i jo mateix estem en curs de muntar una mena d'“Auberge de la jeunesse" per a catalans». Com anota l'editor del volum, Carles-Jordi Guardiola, «serà l’Auberge de la Jeunesse l'Épi d'Or a Boissy-la-Rivière, on s'installaran a començament de març», Carles Riba, Cartes de Carles Riba, vol. 2 (Barcelona: Institut d'Estudis Catalans, 1991), 28, n. 5.

55 Citat per Francesc Vilanova, Carles Pi i Sunyer (1888-1971) (Barcelona: Publicacions de l'Ajuntament de Barcelona, 1995), 193. 
i serveis dependents de diferents administracions», que pot representar tot el que en realitat no es va poder abordar per manca de recursos però que, tanmateix, no es podia abandonar. Hi consten partides per sostenir despeses de butxaca de grups de catalanistes republicans hostatjats en refugis encomanats a diferents institucions fora de l'abast de la Generalitat. També petites partides fixes per a residències que no depenien directament de Presidència. És el cas, per exemple, del Centre d'Hebergement de Montolieu, de l'Auberge de la Jeunesse de Roissy-en-Brie, ${ }^{56}$ del centre d'acolliment de Montauban ${ }^{57}$ i de la residència de Tolosa de Llenguadoc, ${ }^{58}$ que el Govern català no finançà directament. ${ }^{59}$ Altrament, les pressions

56 Bona part de l'abundosa bibliografia prové dels mateixos estadants. En són exemples: Xavier Benguerel, Memòries, 1905-1940 (Madrid/Barcelona: Alfaguara, 1971), 321-323; Sebastià Gasch, París, 1940 (Barcelona: Quaderns Crema, 2001) 85-86 i 115; Mercè Rodoreda, Cartes a l'Anna Murià 1939-1956 (Barcelona: Edicions de les Dones, 1985), 18-20; Mercè Ibarz, Rodoreda, exili i desig (Barcelona: Editorial Empúries, 2008), 47-48; Ferran Canyameres, El gran sapastre (Barcelona: Agut Editor, 1977), 155; Josep M. Balaguer i Maria Campillo, Francesc Trabal: Centenari 1899-1999 (Barcelona: Generalitat de Catalunya, Departament de Cultura, Institució de les Lletres Catalanes, 2001), 30; Xavier Febrés, ed., Joan Oliver - Pere Calders, conversa transcrita per Xavier Febrés (Barcelona: Editorial Laia, 1984), 47; Francesc Trabal, Els contracops de l'enyorança: Escrits de l'exili, edició i pròleg de Maria Campillo (Sabadell: Fundació la Mirada, 2011). Un recull interessant de literatura escrita a l'època per diversos dels seus protagonistes el trobem a Julià Guillamon, ed., Narrativa catalana de l'exili (Barcelona: Galàxia Gutenberg, 2005).

57 Es tracta d'una residència installada en una localitat al nord de Tolosa i destinada, principalment, a elements d'Estat Català.

58 La partida corresponent a la residència de Tolosa és una assignació regular de 10.000 francs mensuals per al que podríem anomenar diners de butxaca, destinada únicament a alguns republicans catalanistes que hi vivien; en cap cas no és una subvenció al comitè organitzador francès en benefici de tots els residents. Així ho deixa clar el mateix Antoni M. Sbert en l'anteriorment citada carta al Dr. Camile Soula (vegeu la nota 52): «Étant donné que les amis, que vous et le Comité de Toulouse avez bien voulu heberger, manquent d'argent de poche et, même, de l'indispensable pour faire face a leurs besoins, nous voulons faire un nouvel effort en vous envoyant francs dix mille de nos revenus du bureau central. Je vous prie encore de distribuer cette somme assisté des personnes les plus qualifies parmi les catalans et selon les besoins, collectifs ou individuels, les plus urgentes», carta d'Antoni M. Sbert al Dr. Camile Soula, 26 de febrer de 1939, ${ }_{5}$ S420, Fons Maria Baldó, Arxiu Municipal de Tolosa de Llenguadoc. Com és sabut, la residència de Tolosa de Llenguadoc depenia totalment del Comité Universitaire Toulousain d'Aide à l'Espagne Républicaine, promogut pel Dr. Camile Soula juntament amb un petit grup de professors universitaris francesos.

59 Francesc Trabal era el seu valedor davant de la Generalitat. Maria Campillo en diu que «des de Tolosa de Llenguadoc i des de Montmorency (al radi de París), la preocupació constant de l'escriptor és la d'atendre el collectiu d'intellectuals i gestionar, mitjançant el seu camp d'influència institucional i política, l'acollida a les residències per a exiliats, primer, i els mitjans per a l'evacuació, després. Així, ajudà diferents nuclis de refugiats i intervingué en l'organització de la residència de Roissy-en- 
constants per augmentar la capacitat de la residència de Montpeller ${ }^{60}$ es traduïren en un augment de les intencions de donar més suport a la residència de Tolosa $i$, parallelament, de promoure una nova residència, però amb un reflex en l'assignació econòmica poc remarcable. ${ }^{61}$ Es destinà, també, en aquest apartat un import menor «per contribuir a l'organització del Camp dels Catalans d'Agde» i una partida més important per a subsidis a l'emigració. Finalment, hi consta una partida minsa per sostenir el centre d'atenció a la massa de refugiats prop de Perpinyà, que és comparable a la que s'assignava a la residència de Tolosa, i que suposa menys d'una desena part del pressupost total. Per poder comparar i entendre millor les dimensions del que comentem, val la pena considerar que el cost mensual de l'administració central de què hem parlat anteriorment s'apropava als 15.000 francs.

La política del SERE, en canvi, que va fomentar algunes residències per a gent gran i per a mutilats, es basava sobretot en el repartiment de subsidis individuals per a persones addictes al Front Popular, oficialment en funció dels càrrecs que havien desenvolupat durant el període republicà i extraoficialment per filiació política. Promoure espais d'acollida per conservar la cultura espanyola i la llengua castellana, que no es consideraven amenaçades en la mateixa mesura que els catalanistes republicans veien que les seves ho estaven, no entrava en els seus paràmetres. Així, la política de la Generalitat no podia convergir, ni poc ni gaire, amb les línies d'acció de Juan Negrín i dels seus seguidors. La Generalitat, de fet, va voler tirar endavant un pla de residències per atendre els membres destacats de les seves institucions, que permetrien promoure la cultura amb ponències,

Brie, on aniria a raure, duent la direcció implícita d'un grup d'escriptors constituït, principalment, pel secretariat de la Institució de les Lletres», Balaguer \& Campillo, Francesc Trabal..., 30.

6o Les places havien anat en augment des que es va crear. Cap al juliol semblava que s'havia arribat al límit de capacitat.

61 En la carta del 2 de juliol de 1939 Antoni M. Sbert va comentar a Companys: «El no haver-se facilitat oportunament els mitjans necessaris per a organitzar el nou Centre o Residència, proposat en el nostre informe (el que es va enviar al SERE el 15 de maig de 1939 [es tracta d'una carta on es demana al Govern central de la República una sèrie de recursos per atendre el grup de catalanistes republicans]), ha obligat a ampliar en unes 75 places el pressupost del Centre de Montpeller a fi que no haguessin d'entrar als camps de concentració i continuar-hi els que han esgotat tots els recursos i esperen poder embarcar cap a Amèrica o obtenir el subsidi, que per el seu càrrec els correspon en alguns casos", 5.12.3, doc. 2-3, Fons Generalitat de Catalunya a l'exili, ANC. 
congressos i publicacions, i que facilitarien a la colònia catalana usar la llengua pròpia amb una certa normalitat i transmetre-la a les noves generacions, així com els costums i les tradicions. ${ }^{62}$ Si no era possible reproduir el model de Montpeller, el pla alternatiu no comportava renunciar a tenir concentrats els millors intellectuals i polítics catalanistes republicans, sinó assumir que el finançament que provenia d'altres organismes implicava renunciar al control polític i al guiatge cultural, circumstància que, finalment, va acabar per dispersar-los.

En parallel a l'activitat de les residències es van atorgar pensions a alguns membres destacats de les institucions catalanes que no hi vivien necessàriament. Observem el fenomen als comptes relatius a l'oficina de Presidència que ens informen de les subvencions atorgades als polítics de més rellevància. ${ }^{63} \mathrm{Hi}$ ha assignacions a vint-i-quatre membres del Parlament de Catalunya, que oscillen entre els 1.000 i els 2.500 francs per persona, que en total ascendeixen a uns 59.000 francs mensuals (una mitjana de 2.458 francs per persona i mes), per bé que no es van fer efectives fins a finals d'estiu del 1939. ${ }^{64}$ Encara que no es pugui considerar sorprenent és tanmateix destacable que només rebessin subsidi els diputats catalanistes republicans i no, en canvi, els comunistes. Per filiació tots havien guanyat l'escó presentant-se per Esquerra Republicana de Catalunya excepte dos: Josep Folch i Folch, del Partit Radical Autònom de les Comarques Tarragonines, ${ }^{65}$ i Pau Romeva, d'Unió Democràtica de Catalunya. Pel que

62 Per fer-se una idea de l'ambient cultural i social de la residència de Montpeller vegeu Alexandre Cirici, Les hores clares (Barcelona: Edicions Destino, 1977) i Miquel Guinart, Memòries d'un militant catalanista (Barcelona: Publicacions de l'Abadia de Montserrat, 1988).

63 Resum de pagaments dels serveis d'assistència catalana corresponent al mes de desembre de 1939, 32.1, Fons Generalitat de Catalunya a l'exili, ANC. No és un resum de despeses en sentit estricte, sinó que més aviat sembla el típic informe d'estat de caixa. No és segur que contingui la informació del desembre del 1939 a mes tancat, ja que és massa gran la diferència entre les consignacions teòriques i els pagaments efectivament realitzats. Probablement és un informe realitzat abans d'acabar el mes, que no conté, doncs, totes les transferències de pagament realitzades sinó només una part.

64 Hem de tenir en compte que el Parlament de Catalunya va ser constituït el 1932 amb 85 escons: 56 d'ERC, 16 de la Lliga Regionalista, 5 de la USC de Joan Comorera i vuit més de partits minoritaris.

65 El Partit Radical Autònom de les Comarques Tarragonines es va constituir per concórrer a les eleccions del 1932 com una escissió del Partit Republicà Radical Autonomista. Va aconseguir quatre escons en una coalició amb Esquerra Republicana, dins la qual es va acabar diluint. Vegeu Isidre Molas, ed., Diccionari dels partits polítics de Catalunya: Segle xx (Barcelona: Enciclopèdia Catalana, 2000), 217 i 266. 
fa als membres del Govern de la Generalitat i del seu president, percebien 63.000 francs al mes. També les assignacions del president Companys (5.00o francs) i dels exconsellers Josep Tarradellas o Antoni M. Sbert (amb 4.00o francs mensuals respectivament) eren suficients per gaudir d'una situació econòmica personal més que folgada. Hi consten, també, partides dedicades a Maria Macià, filla del difunt president, o a la vídua del líder d'Unió Democràtica de Catalunya assassinat pels franquistes, Manuel Carrasco i Formiguera, que va ser la millor retribuïda, amb una assignació mensual que ascendia a 5.000 francs. Altres partides revelen un cert deure moral i de gratitud envers aquells que es consideraven referents polítics de relleu en la història recent de Catalunya o collaboradors més propers al president, com el president del Parlament, Josep Irla; l'exconseller de Seguretat Interior, Artemi Aiguader i Miró; el director general de Propaganda, Jaume Miravitlles; el comissari delegat de la Generalitat de Catalunya a les terres de Lleida, Josep Sastre Torruella, i el comissari delegat de la Generalitat de Catalunya a Tarragona, Ramon Sanahuja.

\section{La cultura i la llengua: pot petit, però de bona confitura}

Les xifres oficials de la Fundació Ramon Llull, en la seva faceta bàsicament de promoció de la cultura, des de l'inici de la seva comptabilitat al mes d'abril fins al desembre del 1939, giren entorn dels 750.000 francs, és a dir, d'uns 65.000 francs mensuals.

Taula 5. Relació de despeses, per conceptes i en francs, de la Fundació Ramon Llull durant els mesos d'agost, setembre i octubre del 1939

\begin{tabular}{lrrr} 
& Ag. & Set. & Oct. \\
\hline Administració & $3.508,45$ & $3.009,70$ & $13.018,65$ \\
\hline Lloguer d'oficines, calefacció & $23.830,80$ & $2.291,60$ & 327,50 \\
\hline Collaboració eventual & $6.518,00$ & $7.014,00$ & $3.546,00$ \\
\hline Biblioteca i adquisició d'obres & $1.024,00$ & $1.913,70$ & $13.365,80$ \\
\hline Diversos & $3.201,00$ & 619,00 & $1.057,50$
\end{tabular}


Ag.

Set.

Oct.

\begin{tabular}{lrrr}
\hline Ajuda als intellectuals & $12.387,05$ & $24.478,00$ & $8.757,00$ \\
\hline Mobiliari i installació & $26.396,50$ & $11.992,90$ & $16.003,00$ \\
\hline
\end{tabular}

$76.865,80$

Restitucions

$40.000,00$

Total setembre

$91.318,90$

Publicacions

$25.000,00$

Restitucions

$40.000,00$

Total octubre

$121.075,45$

Font. 7.2.6, doc. 2, fons Artea, ANC

Les partides de lloguer i de mobiliari i installació són quasi inexistents entre els mesos de març i juliol del 1939, mentre que en aquest document veiem que durant els mesos d'agost a octubre són, en canvi, considerables. Això ens permet deduir que no hi va haver una veritable seu de la Fundació Ramon Llull com a promotora cultural fins a l'estiu del 1939, i que, probablement, va compartir anteriorment els locals amb alguna altra institució que es feia càrrec d'aquestes despeses. ${ }^{66}$ Entenem que des de l'acord econòmic amb la JARE, l'activitat cultural pren una nova volada i s'independitza d'altres iniciatives pel que fa a la gestió i a l'espai físic.

El capítol sobre «collaboració eventual», per la seva banda, fa referència, possiblement, als diners destinats a pagar les contribucions de diversos

66 Relació de despeses, per conceptes, de la Fundació Ramon Llull durant els mesos d'agost, setembre i octubre del 1939, 7.2.6, doc. 2, Fons Generalitat de Catalunya a l'exili, ANC. Sembla un resum de gestió utilitzat per exposar alguna qüestió o defensar una política determinada davant d'alguna persona o grup influent. Coincideix amb un document rebut per Carles Pi i Sunyer a Londres a començaments del 1940, que és datat el 31 de desembre de 1939, per bé que presenta una diferència: el darrer inclou les despeses des del març del 1939 fins al desembre del mateix any, mentre que el document d'Artea només recull les produïdes des de l'agost fins a l'octubre del 1939. El document és citat per Maria Campillo i Francesc Vilanova, ed., La cultura catalana en el primer exili, 1939-1940: Cartes d'escriptors, intellectuals i científics (Barcelona: Fundació Carles Pi i Sunyer, 200o), 29. Aquests números també coincideixen quasi idènticament amb el que va publicar Antoni M. Sbert a la Revista de Catalunya; vegeu Sbert, «Memòria de la Fundació...». 
intellectuals exiliats a l'obra cultural de la Fundació —és a dir, els articles, illustracions, etc.- , que es necessitaven per donar contingut a les publicacions d'exili com El Poble Català o la Revista de Catalunya ${ }^{67}$ Aquests ajuts de caràcter indirecte destinats a intellectuals exiliats tindran una partida d'entre 5.000 i 6.000 francs mensuals destinada expressament a aquest objectiu. ${ }^{68}$

La Fundació Ramon Llull dedicarà, també, entre els mesos d'agost i desembre del 1939, una partida de 5.631,15 francs a l'adquisició de llibres. Tenint en compte que en aquella època un llibre costava al voltant de 15 francs, podem deduir que es van comprar uns 35 o llibres en cinc mesos. ${ }^{69}$ En la mateixa línia, es van destinar 34.297,75 francs a l'adquisició d'un fons d'obres d'art, que principalment devia ser d'artistes catalans exiliats, seguint el mateix criteri que amb la partida anterior.

Els ajuts a intellectuals, en canvi, foren considerables durant aquest període, fins a arribar als 113.532,55 francs des de l'abril fins al desembre del 1939. Aquesta ajuda es materialitzà principalment en subvencions ad personam per a una llista de noms que anà variant. A partir de la tardor del 1939 també es dedicaren alguns recursos a ajudar estudiants amb beques d'estudi i quantitats força importants per a publicacions..$^{70}$

Com hem vist, de manera anàloga a com ho van anar fent els diferents grups polítics a l'exili, ${ }^{71}$ els representants de la Generalitat van fer pivotar

67 Carta de Carles Riba a Santiago Pey, 4 de maig de 1940, dins Riba, Cartes..., vol. 2, 125.

68 A propòsit d'aquest fet, Alexandre Cirici esmenta a les memòries Les hores clares de manera planera i directa com li van pagar 3.000 francs per treballar fent illustracions per a la Revista de Catalunya. Cirici, Les hores clares, 197.

69 N'és un exemple la factura de la Librairie Garnier Frères de París, del 26 juliol de 1939, 7.2.2., doc. 85, Fons Generalitat de Catalunya a l'exili, ANC.

70 «A París, la Fundació Ramon Llull, la més ambiciosa de tot l'exili, assegurava edicions catalanes de qualitat. Una d'elles era la Revista de Catalunya», Josep Pous i Pagès, Memòries d'exili, edició a cura de M. Àngels Bosch (Barcelona: Editorial Afers, 2002), 20.

71 Milagrosa Romero Samper ens parla principalment dels comitès d'ajuda controlats per Negrín i els comunistes, com ara el CICIAER (Comité Internacional de Coordinación y de Información para la Ayuda a la España Republicana), que canalitzava l'ajuda a través de l'CSI (Central Sanitaria Internacional) i del Servicio Internacional para la Infancia; vegeu Milagrosa Romero Samper, La oposición durante el franquismo, vol. 3, El exilio republicano (Madrid: Ediciones Encuentro, 2005), 8o. Marie-Claude Rafaneau Boj també parla de la Casa de los Heridos, reservada als antics brigadistes internacionals; vegeu Marie-Claude Rafaneau Boj, Los campos de concentración de los refugiados españoles en Francia: 1939-1945 (Barcelona: Ediciones Omega, 1995), 153. Per la seva banda, les historiadores Queralt Solé 
la seva activitat al voltant de diversos comitès i fundacions, que esdevingueren pantalles legals imprescindibles per portar a terme els seus objectius assistencials i de preservació i foment de la cultura. En aquest marc, trobem el que es va anomenar Centre d'Aide aux Intellectuels d'Espagne (d'ara endavant, CAIE), forma jurídica d'un organisme continuador del Comité d'Aide aux Intellectuels Catalans (CAIC).

El CAIC es va constituir a França la darrera tardor de la guerra amb l'ajuda d'Enric Roig, que en va ser el tresorer i la persona de confiança de la Generalitat, ${ }^{72}$ amb l'objectiu d'ajudar quaranta-dos membres de la Institució de les Lletres Catalanes. ${ }^{73}$ Després d'assistir modestament a alguns intellectuals durant els darrers mesos de guerra, quan l'exili ja era una realitat, es va promoure la transformació d'aquest comitè en una organització no governamental d'assistència als intellectuals de més capacitat i rellevància. El nou organisme es va anomenar Centre d'Aide aux Intellectuels d'Espagne ${ }^{74}$ per raons que se'ns escapen, aquest cop també obert a no catalans. Per començar va promoure una prospecció financera que permetria endegar les tasques d'assistència al nivell que es requerís al més aviat possible. El prestigi del patronat francès va ser suficient per recollir en

i Gemma Caballer recorden diversos d'aquests organismes, com ara el Comité National Catholique de Secours aux Refugiés d'Espagne o el Comité Catholique de Secours pour les Infants Espagnols, de tendència evidentment catòlica; la Ligue International des Amis des Basques (secció francesa), nacionalista basca, i diversos organismes de caràcter internacional com el Comité National Britannique d'Aide a l'Espagne, el National Joint Committee for the Spanish Relief, el Comité Central des Refugiés de Paris o la International Commission for the Assistance of Spanish Child Refugees, entre d'altres. Vegeu Queralt Solé i Gemma Caballer, «Aproximación biográfica a Josep Maria Trias i Peitx (Barcelona, 1900 - Prada de Conflent, 1979): un hombre de Unió Democràtica de Catalunya (UDC) clave para el exilio republicano en los campos de internamiento franceses», Pasado y Memoria. Revista de Historia Contemporánea 12/36 (2013): 174. doi: https://doi.org/10.14198/PASADO2013.12.o6.

72 Enric Roig i Querol (Barcelona, 1901 - Créteil, 1989) residia a París com a mínim des del juliol del 1938 i treballava al número 7 del bulevard Haussmann de París, seu de l'oficina de la Generalitat a la capital francesa. Des d'allà, com hem dit, gestionava determinats fons de la Generalitat, fet que explicaria la rapidesa amb què va disposar de recursos econòmics per atendre les necessitats dels exiliats catalans. Vegeu la carta 1008 de Carles Riba a Enric Roig i Querol, del 7 de febrer de 1939, dins Cartes de Carles Riba, vol. 4 (Barcelona: Institut d'Estudis Catalans, 2005).

73 Model de carta signat a París, enviat a diversos intellectuals francesos pel citat comitè en els seus inicis. No hi consta la data, tot i que el més probable és que sigui de l'octubre o del novembre del 1938, 5.8.3, doc. 1, Fons Generalitat de Catalunya a l'exili, ANC.

74 «Rapport sur l'activité du Centre d'Aide aux Intellectuels d'Espagne», 25.3.1, doc. 2-8, Fons Generalitat de Catalunya a l'exili, ANC. 
poques setmanes, mitjançant petites subscripcions individuals, la suma de 30.000 francs, que també procedien de filantrops nord-americans i d'altres d'anònims que van donar quantitats considerables durant els primers mesos. ${ }^{75} \mathrm{El} \mathrm{CAIE} \mathrm{disposava} \mathrm{de} \mathrm{centres} \mathrm{locals} \mathrm{creats} \mathrm{per} \mathrm{coordinar} \mathrm{les}$ donacions, a través dels quals els membres del patronat també es movien entre els filantrops francesos: amb l'ajuda del ministre d'Economia, Raymond Patenôtre, van aconseguir uns 50.000 francs entre diverses aportacions. Finalment, es van publicar amb poc èxit algunes subscripcions a diaris de més o menys tiratge com el Journal Marianne, i dues breus notes aparegudes als diaris L'Ordre i L'CEuvre, l'única publicitat que se'n va fer i que tanmateix no va ser eficaç. Amb aquests mitjans, entre el 15 de març i el 25 de setembre de 1939 es van recaptar 108.256 francs.

La primera tasca, i la més urgent, va consistir a treure el màxim nombre d'intellectuals, escriptors i artistes dels camps de concentració, amb l'objectiu final d'alliberar-los a tots, malgrat les dificultats financeres i, sobretot, administratives. El delegat del CAIE més actiu al Midi francès va ser el dirigent d'Unió Democràtica de Catalunya Josep Maria Trias i Peitx, membre fundador del Comité National Catholique de Secours aux Refugiés d'Espagne, casat amb la periodista i escriptora francesa Clara Candiani. ${ }^{76}$ Ambdós van fer grans esforços humanitaris a favor dels refugiats catalans i espanyols durant el 1939 i, a partir del 1940, també a favor d'altres nacionalitats, especialment jueus. ${ }^{77}$ Els rebuts conservats indiquen que es dedicava a fer arribar part de les subvencions destinades als intellectuals que residien als camps d'internament..$^{7}$

75 a) Donació de 500 dòlars (18.825 francs) de Henry Church. Extracte bancari del Banc Morgan \& Co. a favor del CAIE, xec n.11712, 31 de març de 1939, 2.2.1, doc. 20, Fons Generalitat de Catalunya a l'exili, ANC. $b$ ) Donació de 100 dòlars (3.76o francs) d'origen desconegut. Extracte bancari de The National City Bank of New York a França a favor del CAIE, compte 41104, xec n. 52106, 9 de maig de 1939, 2.2.1, doc. 104-105, Fons Generalitat de Catalunya a l'exili, ANC.

76 Amb ells va collaborar estretament Maurici Serrahima durant els anys 1939-1940. Vegeu Maurici Serrahima, Memòries de la guerra i de l'exili, II: 1939-1940 (Barcelona: Edicions 62, 1981), 286 i s.

77 Sobre Josep M. Trias i Peitx i la seva activitat assistencial vegeu Solé \& Caballer, «Aproximación biográfica a Josep Maria Trias i Peitx...».

78 És el cas, per exemple, del rebut signat per Jaume Àngel Aymerich del camp n. 3 d'Agde per la recepció de 200 francs entregats per Josep M. Trias i Peitx el 27 de juliol de 1939, 2.2.2, doc. 87, Fons Generalitat de Catalunya a l'exili, ANC. És més definitiva la carta amb l'estat de comptes que va en- 
La iniciativa més important del CAIE, però, va ser la residència de Roissyen-Brie, de què hem parlat amb anterioritat. En va tenir cura Clara Candiani, que feia d'enllaç entre el CAIE i la residència. Els comptes mostren que estava sobrecarregada d'hostes, particularment en els darrers dies de l'estiu del 1939. La situació va esdevenir insostenible a partir del mes de setembre del 1939 per causa de les altes despeses dels residents, els visats d'embarcament a Amèrica, les subvencions directes individuals i el material enviat als camps d'internament, però també per la caiguda dràstica de les aportacions dels intellectuals francesos després que França entrés en una nova guerra amb Alemanya. L'exclamació de l'estadant de Roissyen-Brie, Sebastià Gasch, «Ils sont là!»,79 que es va fer popular uns mesos després, no va trigar a ser pronunciada en aquelles contrades, cosa que va fer anar-se'n en orris tota la feina que el CAIE havia realitzat fins llavors.

Taula 6. Resum de despeses del CAIE des del 15 de març fins al 25 de setembre de 1939

\begin{tabular}{lr} 
Despeses & Francs \\
\hline Alberg de refugiats & $80.000,00$ \\
\hline Subvencions individuals & $16.000,00$ \\
\hline Material d'acomodament & $2.700,00$ \\
\hline Visats de passaport & $4.750,00$ \\
\hline Tabac, llibres, material de papereria & $1.800,00$ \\
\hline Factures d'impressions i correspondència & $2.000,00$ \\
\hline Total despeses CAIE & $107.250,00$ \\
\hline
\end{tabular}

Font. 25.3.1, doc. 7, fons Artea, ANC

La guerra, com és natural, va espantar a tothom a França i els intellectuals francesos no en van ser una excepció. Davant la pròpia amenaça,

viar el diputat d’UDC a Enric Roig i Querol en què exposava la liquidació d'entrades i sortides dels mesos de juny i de juliol del 1939, 2.2.2, doc. 88, ibídem.

79 Gasch, París, 1940, 10. 
van preferir limitar les seves aportacions, reservar-les o desviar-les cap als seus compatriotes. En conseqüència, el CAIE es va dissoldre durant una reunió a l'inici de la tardor del 1939, i se'n va notificar la dissolució i el tancament pocs dies després als intellectuals residents a Roissy-en-Brie amb una simple carta d'avís. ${ }^{80}$

Com es veu, el CAIE, malgrat tenir uns ingressos modestos, ${ }^{81}$ va poder dur a terme una tasca lloable i eficaç a favor dels intellectuals exiliats, particularment dels catalans. ${ }^{82}$ No sembla que la Generalitat tingués una influència directa sobre el CAIE, atès que cap membre del patronat era català, excepte el tresorer, una circumstància que no era menor. Enric Roig i Querol va realitzar una labor minuciosa i acurada a l'hora de gestionar-ne els cabals. Quan s'analitzen les trameses de diners del CAIE a intellectuals, ${ }^{8_{3}}$ es conclou que el tresorer procurava que els beneficiaris fossin sovint catalans, fet que potser va passar desapercebut als membres del patronat. ${ }^{84}$ Les transferències destinades a Roissy-en-Brie es feien de vegades directament a Francesc Trabal, ${ }^{85}$ que les emprava per comprar articles de primera necessitat per als seus residents; en ocasions, però, s'enviaven a l'administrador, el Sr. Samson, o es feien arribar a través del Comité Français pour le Parrainage de Familles Espagnoles et pour l'Ai-

8o Carta de P. L. Berthaud a Lucien Samson, administrador de Roissy-en-Brie, 10 d'octubre de 1939, 2.2.2, doc. 161, Fons Generalitat de Catalunya a l'exili, ANC.

81 La informació continguda a la taula 6 es complementa amb el compte d'explotació del CAIE fins que es va dissoldre, 19 d'octubre de 1939, 5.8.4, doc. 8, ibídem.

82 N'hi havia una vintena que no eren catalans. Anna Murià, en citar el seu company Agustí Bartra, ens explica el seu pas per Roissy-en-Brie. Anna Murià, L'obra de Bartra. Assaig d'una aproximació (Barcelona: Editorial Pòrtic, 1992).

83 Extractes del compte 2265.34 del Ministère des Postes, Télégraphes et Téléphones francès i avisos de remeses de xecs del compte n. 41.104 de The National City Bank of New York a França, 2.2.2 i 2.2.1, Fons Generalitat de Catalunya a l'exili, ANC. Un exemple d'això podria ser un avís de remesa de xecs per valor de 12.500 francs provinents dels Estats Units a favor de Lucien Samson, administrador de Roissy-en-Brie, 3 d'agost de 1939; 2.2.2, doc. 110, ibídem.

84 Podem trobar nombrosos justificants de transferències fetes a Francesc Trabal, Anna Murià, Jaume Balmes, Domènec Guansé, Xavier Benguerel o Cèsar August Jordana, entre d'altres, a 2.2.2, ibídem. El nombre de catalans objecte de les transferències de diners és molt superior al d'intellectuals d'altres orígens.

85 Avís de recepció de Francesc Trabal al CAIE per import de 1.00o francs, 18 d'abril de 1939, 2.2.2, doc. 12, ibídem. 
de aux Réfugies, ${ }^{86}$ una de les múltiples entitats creades aquells dies per assistir els exiliats.

El suport destinat a la cultura catalana i a la supervivència dels seus màxims exponents es va afrontar amb pocs recursos, però, aparentment, prou ben dirigits i sostinguts amb esforços lloables de molta gent obcecada perquè no es perdessin tants anys de lluita en el no-res d'un exili caòtic. Es podria dir, doncs, que la cultura catalana sí que va ser una prioritat per a la Generalitat exiliada, que, directament o indirecta, va maldar per fomentar-la.

\section{Els exiliats catalans de base: plorava perquè no tenia sabates fins que vaig veure un home que no tenia peus}

Ja des del començament del seu pelegrinatge per terres d'exili, els catalanistes republicans de base van comptar amb l'ajuda de l'esmentada CEvre d'Entraide aux Républicains Catalans (OERC) — també anomenada Entr'aide aux Républicains Catalans (ERC) - , organisme constituït a Perpinyà el 3 de febrer de 1939 per facilitar assistència material als refugiats que mancaven del més indispensable per sobreviure. La delegació de Perpinyà, situada al número 9 del carrer Oliva, inicialment va ser encomanada a Pere Bosch i Gimpera, que va rebre l'ajuda de Carles Martí i Feced

86 El Comité Français pour le Parrainage de Familles Espagnoles et pour l’Aide aux Réfugies era una organització no governamental, amb seu al número 13 del carrer Alphonse-Daudet de París. Tenia un patronat compost per una vintena d'intellectuals, periodistes i polítics, amb Roger Lardenois al capdavant com a secretari general i Georges Lanfry com a tresorer. Durant la Guerra Civil va fer labor social a Catalunya, i després de la guerra va atendre nombrosos refugiats catalans i espanyols a França. Entre altres accions, va subvencionar durant un temps la residència de Roissy-en-Brie. Va collaborar en el famós molí de Bierville, a Boissy-la-Rivière, propietat de Marc Sagnier, i en la residència del Dr. Camile Soula a Tolosa de Llenguadoc. No conec l'import exacte de cadascuna d'aquestes aportacions, només que aquest comitè va recollir un total de 100.424 francs des que es va crear, amb donacions fetes a favor de les víctimes de la guerra espanyola. Suposadament, doncs, tenien contactes amb la Generalitat de Catalunya, però el fet de no tenir a ningú directament implicat en el seu si hauria fet que encara fos més difícil d'influir-hi en benefici dels refugiats catalanistes republicans. M'he basat en Roger Lardenois, Memòria d'activitats del Comité Français pour le Parrainage de Familles Espagnoles et pour l’Aide aux Réfugies, París, 29 de març de 1939, 5.8.4, doc. 10-12, Fons Generalitat de Catalunya a l'exili, ANC. En seria un exemple l'enviament de 5.00o francs del CAIE a Roger Lardenois per atendre les despeses de Roissy-en-Brie, 4 maig de 1939, 2.2.2, doc. 17, ibídem. 
i de Ramon Frontera ${ }^{87} \mathrm{El}$ mes d'abril del mateix any, Frontera va prendre la direcció de l'OERC, la qual cosa va facilitar que l'exconseller de Justícia marxés cap a Londres i que Carles Martí i Feced fos nomenat cap del Bureau d'Information, que s'estava organitzant en aquells moments a París.

Per entendre millor aquesta delegació oficial de la Generalitat de Catalunya a Perpinyà prop dels camps de concentració, tenim alguns documents inèdits interessants que aporten dades sobre el volum de recursos que la sostenien ${ }^{88}$ L'oficina tenia un pressupost mensual de 8.400 francs, ${ }^{89}$ 4.650 del quals eren per a personal d'oficina, Màrius Calvet i tres persones més, de qui només coneixem els cognoms (Falguera, Marina i Montserrat). ${ }^{\circ}$ La previsió de despesa es repartia entre el lloguer del local i altres costos d'estada ( 950 francs), la correspondència i el material d'oficina (500 francs), els serveis als camps (1.00o francs) i els viatges (1.200 francs). Coneixent les partides que les oficines de París destinaven a la delegació de Perpinyà, es pot constatar que la política de la Generalitat a l'exili, amb referència a la gran massa de refugiats, no passava de brindar suport moral, atès que els recursos enviats només arribaven per sostenir una petita oficina d'atenció als republicans catalanistes exiliats, però sense pressupost per fer gairebé res més.

En un primer moment, es cobriren la prestació de serveis, fins que s'esgotaren els recursos per fer-ho, que probablement provenien d'algun petit

87 Ramon Frontera havia estat alcalde de l'Hospitalet de Llobregat fins al mes de setembre del 1936. A partir del 1937, amb Carles Pi i Sunyer, fou escollit president del Consell de l'Escola Nova Unificada i sotssecretari de Cultura sota les seves ordres fins al final de la guerra. Va ser responsable directe de l'evacuació dels principals intellectuals catalans. Vegeu Pere Bosch i Gimpera, Memòries (Barcelona: Edicions 62, 1980), 296-297, i Carles Pi i Sunyer, 1939: Memòries del primer exili (Barcelona: Fundació Carles Pi i Sunyer, 2000), 45.

88 Memòria d'activitat redactada en anglès i en francès, Perpinyà, 30 de juny de 1939, 24.1.3, doc. 1-22, Fons Generalitat de Catalunya a l'exili, ANC. Memòria d'activitat redactada en castellà, Perpinyà, desembre del 1939, 7.4.2, doc. 1-22, ibídem. Ingressos i despeses de la delegació de Perpinyà corresponents al mes de juny del 1939 i annex, 24.1.1, doc. 732-741, ibídem. També ha aportat informació l'epistolari intercanviat entre la central de París i la delegació de la capital de la Catalunya Nord, conservat al mateix arxiu.

89 Nota mecanografiada sense data, titulada «Pressupost mensual per al funcionament de la Delegació de Perpinyà», 24.1.5, doc. 14, Fons Generalitat de Catalunya a l'exili, ANC.

90 Possiblement es tracti de J. Falguera, secretari de Carles Martí i Feced, exconseller de Governació, Finances i Cultura del Govern de la Generalitat, nomenat el 5 de maig de 1937 —vegeu Sauret, L'exili polític català, 21-, i de Lluís Montserrat, funcionari de Cultura. 
fons dels pressupostos de la Generalitat que els mateixos organitzadors podien haver portat de Catalunya durant la fugida precipitada i podien haver derivat després a la causa benèfica que tenien entre mans. Un cop exhaurits, acudiren a organitzacions d'ajuda humanitària, que, segons sembla, contribuïren principalment amb béns en espècie, més que no pas amb diner líquid. Els primers a collaborar-hi van ser els quàquers americans, que, per mitjà de la Dra. Russell, la seva delegada a Perpinyà, feren arribar abundants recursos de diversos llocs per atendre els refugiats catalans.

La memòria del mes de juny del 1939, escrita en anglès per als quàquers, ${ }^{91}$ els principals benefactors de la seva activitat, i en francès per a les autoritats i comitès d'ajuda del país veí, fa evident que l'activitat realitzada entre el febrer i el juny del 1939 es va centrar en cinc aspectes: atenció als refugiats internats en camps, cens de catalans, servei d'informació als refugiats, servei de restaurant a Perpinyà i atenció mèdica personalitzada als exiliats malalts. Així, pel que fa a l'atenció de refugiats, durant els primers mesos d'exili es van pagar segells per a més de 6.0oo cartes i es van subvencionar 200 telegrames enviats a Espanya, a França i a països tercers, i entre el febrer i l'abril del 1939 es van distribuir entre els refugiats als camps més de 29.000 cartes rebudes. Altrament, el cens de catalans internats als camps revela que al final del maig del 1939 la xifra total de catalans als camps del sud de França era de 41.140,92 i que es van bolcar específicament en els 9.000 catalans traslladats a les seves instàncies al camp número 3 d'Agda. El servei d'informació que connectava els internats amb les seves famílies va ser també de summa importància durant aquells mesos, fins al punt que va atendre i contestar, entre el febrer i el maig del 1939, un total de 23.090 peticions d'informació.

El servei més costós en termes econòmics, però, va ser el de restaurant, que servia una mitjana de 200 persones al dia a la ciutat de Perpinyà, i que estava dirigit a la població flotant d'estadants catalans sense recursos,

91 En una carta de Ramon Frontera a Carles Martí i Feced, li comenta que la memòria en anglès que s'hi adjunta l'han elaborat per lliurar-la a la delegada dels quàquers a Perpinyà, la Dra. Russell. Perpinyà, 3 de juliol de 1939, 24.1.2, doc. 17-18, Fons Generalitat de Catalunya a l'exili, ANC.

92 Antoni M. Sbert, en el seu informe de gestió de la Fundació Ramon Llull del gener del 1940, comenta que la xifra total de l'emigració catalana ultrapassava els 100.000, un 60\% dels quals havien estat censats. 
acabats de sortir dels camps, que necessitaven el més indispensable per alimentar-se. Segons els seus càlculs, calien 7,60 francs per persona i dia. Aquest servei de cantina, que funcionava des del començament de l'exili, es va veure amenaçat al cap de poc temps per manca de recursos, circumstància que es va combatre amb restriccions i mercès a l'ajuda excepcional del SERE i després de la JARE. Finalment, l'atenció mèdica dels exiliats va esdevenir un ressort clau de l'estructura d'atenció humanitària dels membres d'ERC a Perpinyà. Els refugiats que patien les inclemències del temps i la precarietat alimentària dels camps sovint eren víctimes d'afeccions cutànies, problemes cardíacs, infeccions respiratòries i colitis. Aviat, sota la direcció del Dr. Pumarola primer i del Dr. Armendares després, quan el primer va marxar cap a Mèxic, es va crear una policlínica que va obrir 448 expedients entre el 15 de març i el 15 de juny de 1939. En total, en el primer semestre del 1939 s'hi van visitar 2.836 pacients, que, juntament amb els lactants a qui es proporcionava alimentació suplementària i vacunes, van representar una càrrega financera pesada per a la petita oficina del carrer Oliva. En conseqüència, el servei mèdic va ser suspès en diverses ocasions, com, per exemple, a darreries de juny del 1939. La visita dels quàquers, esmentada abans, va facilitar que es comprometessin a sufragar els 2.800 francs mensuals que costava el servei d'assistència mèdica.

Sembla que a partir de la segona meitat del 1939, amb l'alleugeriment dels camps i la consecució de millores econòmiques, la situació va canviar. A partir de llavors les noves necessitats es van centrar en l'atenció dels desnodrits i dels 50.000 catalans mal pagats que eren a les Companyies de Treballadors Estrangers, pels quals es va sollicitar el suport obert de la JARE. Emparant-se en l'organització que ja tenien muntada, amb magatzems i tallers, van considerar factible, des de Perpinyà, l'atenció als milers de catalans que treballaven repartits arreu del país. ${ }^{93}$ Durant el darrer semestre del 1939 l'activitat va continuar i es va incrementar. Malgrat la prohibició dictada des del mes de desembre per les autoritats militars franceses, les visites als camps seguien; els paquets entregats (407), les cartes lliurades (1.356) i enviades (865), i les nombroses gestions a favor dels

93 Memòria de l'Euvre d'Entr'aide aux Républicains Catalans, Perpinyà, desembre del 1939, 7.4.2, doc. 10, Fons Generalitat de Catalunya a l'exili, ANC. 
internats van ser una constant durant el darrer mes de l'any. El servei mèdic i d'informació va continuar funcionant a bon ritme si el comparem amb l'activitat registrada fins al mes de juny.

Les dades financeres que es poden extreure de les dues memòries i de l'extracte de moviments de caixa del mes de juny i de mig juliol del 1939 aporten les xifres següents, que són molt útils per fer-se càrrec del volum econòmic que suposava l'atenció a una gran multitud de persones.

\section{Taula 7. Resum de despeses, en francs, dels serveis d'assistència de l'CEuvre d'Entr'Aide aux Républicains Catalans a Perpinyà (juny-desembre 1939)}

\begin{tabular}{|c|c|c|c|c|c|c|c|c|}
\hline & & Juny & Jul.* & $A g .{ }^{* *}$ & Set. & Oct. & Nov. & Des. \\
\hline \multirow[t]{3}{*}{$\begin{array}{l}\text { 1. Despeses } \\
\text { oficina OERC }\end{array}$} & $\begin{array}{l}\text { Nòmines } \\
\text { personal oficines } \\
\text { i metges }\end{array}$ & $11.300,00$ & $4.655,00$ & - & $12.725,00$ & $10.000,00$ & $10.400,00$ & $13.952,00$ \\
\hline & $\begin{array}{l}\text { Viatges } \\
\text { (automòbil) }\end{array}$ & $2.953,00$ & 896,60 & - & & & & \\
\hline & Material oficina & $2.279,55$ & 424,10 & - & & & & \\
\hline $\begin{array}{l}\text { 2. Atenció } \\
\text { mèdica }\end{array}$ & $\begin{array}{l}\text { Despeses } \\
\text { farmàcia }\end{array}$ & 596,00 & 823,90 & - & $8.883,90$ & $14.327,20$ & $9.753,20$ & $8.982,50$ \\
\hline \multirow[t]{3}{*}{$\begin{array}{l}\text { 3. Atenció als } \\
\text { camps }\end{array}$} & $\begin{array}{l}\text { Despeses atenció } \\
\text { camps }\end{array}$ & 971,15 & 135,20 & - & $6.432,05$ & $5.012,00$ & $6.482,00$ & $5.905,00$ \\
\hline & Correspondència & 708,05 & 303,60 & 一 & & & & \\
\hline & $\begin{array}{l}\text { Premsa pels } \\
\text { camps }\end{array}$ & 95,00 & 30,50 & - & & & & \\
\hline \multirow{4}{*}{$\begin{array}{l}\text { 4. Atenció } \\
\text { als refugiats } \\
\text { sortits dels } \\
\text { camps }\end{array}$} & $\begin{array}{l}\text { Auxilis a refugiats } \\
\text { sortits dels camps }\end{array}$ & $4.866,60$ & $2.189,90$ & - & 0,00 & 0,00 & $2.240,00$ & $2.830,00$ \\
\hline & $\begin{array}{l}\text { Tiquets } \\
\text { restaurant }\end{array}$ & $19.722,00$ & 775,20 & - & & & & \\
\hline & $\begin{array}{l}\text { Bitllets de tren } \\
\text { pagats }\end{array}$ & & & & $1.358,25$ & 834,50 & 0,00 & 0,00 \\
\hline & $\begin{array}{l}\text { Total despeses } \\
\text { OERC }\end{array}$ & $43.491,35$ & $10.234,00$ & - & $29.399,20$ & $30.173,70$ & $28.875,20$ & $31.669,50$ \\
\hline
\end{tabular}

*El mes de juliol és només fins al dia 15.

**No disposem de les dades del mes d'agost del 1939.

Font. Elaboració pròpia a partir de 7.4.2, fons Artea, d’ANC 
Taula 8. Distribució d’ajuda procedent de beneficència el 1939

\begin{tabular}{lrrrr} 
& Set.. & Oct. & Nov. & Des. \\
\hline Pots de llet distribuïts & 2016 & 2393 & 3582 & 3423 \\
Peces de roba distribuïdes & 1723 & 1618 & 1918 & 2029 \\
Visites mèdiques & 764 & 865 & 759 & 720 \\
N. viatges als camps & 12 & 21 & 23 & 16 \\
Paquets entregats & 138 & 130 & 442 & 631 \\
Cartes lliurades & 4211 & 5250 & 2310 & 1356 \\
Cartes enviades & 832 & 963 & 913 & 860 \\
Telegrames pagats & 53 & 44 & 34 & 15
\end{tabular}

Font. Elaboració pròpia a partir de 24.1.3, fons Artea, d’ANC

L'anàlisi del resum econòmic de l'OERC ens revela que tenia força activitat malgrat ser un organisme petit i, en el seu conjunt, només una gota en un immens oceà de misèria. Entre 40.000 i 50.000 catalans internats en camps, que malvivien en condicions duríssimes, hi van ser atesos encara que fos amb molt pocs recursos: la despesa mitjana mensual per refugiat no va arribar a un franc per persona, mentre que el cost mitjà mensual per exiliat català a la residència de Montpeller s'apropava als 450 francs — una xifra que podríem fer extensiva a la resta de residències de perfil similar, o que les subvencions dels alts càrrecs rondaven entre els 1.000 i els 5.000 francs mensuals per persona. Les conclusions es desprenen per si soles.

A pesar dels grans esforços del poc personal de la petita delegació de Perpinyà, l'ajuda procedent de donatius en espècie, com roba o llet, va ser minsa: un pot de llet al mes per cada quinze interns o una peça de roba entregada mensualment per cada vint-i-cinc refugiats eren clarament insuficients. ${ }^{94}$ Les cartes intercanviades entre Perpinyà i París reflecteixen

94 «We are anxious to do more and more for our people. Unfortunately we have no capital, no founds, no any powerful organism backing our activities. All we possessed we have given. Needs and aims of refugees increase more and more with the time [...]. We ourselves, instead of being satisfied with our labour - so intense and of profit as it has been-it seems us evidently insufficient and not so wide as it must be. We take pains to improve and to increase our work and it is impossible to do it 
sovint la idea que els representants del Govern a París no estaven gaire compromesos amb aquesta comesa humanitària, si més no en termes econòmics. El to irritat dels representants de la delegació de Perpinyà que destillen les cartes dirigides a París així ho fa entreveure. La delegació sollicitava cabals constantment a la central de París; 95 l'enuig que es desprèn dels epistolaris ens aporta una imatge de tensió creixent, deguda a l'asimetria a l'hora de repartir recursos per a les tasques d'alta volada cultural o de política superior i les d'atenció als militants de base. ${ }^{96} \mathrm{Mal}-$ grat la migradesa dels recursos que van rebre des de la capital de França — des de París estant, Perpinyà quedava lluny — és innegable la feina assistencial que van dur a terme els membres de la delegació de Perpinyà.

Com hem vist, doncs, malgrat que al començament del 1940 el SERE va abandonar el suport als refugiats a França, un servei que va passar a recaure en la JARE, aquesta va ser relativament capaç d'assumir les noves responsabilitats. ${ }^{97}$ El resultat d'aquest darrer acord i de l'esquema de despeses, que ja no va variar substancialment, va ser que la Generalitat de Catalunya es va conformar durant el primer exili a fer una política

without the cooperation of other organisms with strong backings», Rapport Entr'aide aux Républicains Catalans, Perpinyà, 30 juny del 1939, 24.1.3, doc. 10, Fons Generalitat de Catalunya a l'exili, ANC.

95 «Fa quatre mesos que s'usa el meu cotxe per a les visites als camps i demés conveniències del Bureau de Perpinyà [...]. Doncs bé, heu pagat solament la gasolina i una reparació que al principi va fer-se. Per amortització o desgast del cotxe, ni cinc cèntims [...]. El cotxe ha recorregut $10.230 \mathrm{~km}$ des del mes de març fins a la data (28/o6/1939). [...] Crec que em mereixo dos mil francs com a amortització del cotxe», carta de Màrius Calvet a Josep Tarradellas, datada a Perpinyà el 28 de juny de 1939, 24.1.1, doc. 470, ibídem.

96 «No vull parlar-te de que encara no he rebut el gir telegràfic, ni tampoc que per cobrar la gent aquesta setmana, com tantes altres vegades, si he volgut evitar que alguns d'ells no mengin, els he hagut de pagar de la meva butxaca, amb tot i que per raons prou conegudes per tu, la meva situació econòmica en aquests moments, no és igual que setmanes enrere. Com tampoc et diré que he hagut de deixar el servei d'atencions dels camps i de pagar factures per manca de disponibilitat», carta de Ramon Frontera a Carles Martí i Feced, datada a Perpinyà el 3 de juliol de 1939, 24.1.2, doc. 17-18, ibídem. O també: «Recorda’t amic Feced, que des de fa molts dies - i com tu ja saps- estic sense disponibilitats. Sembla que demani caritat, però mentre i tant no es transformi l'organització actual, vosaltres coneixeu prou bé quines són les despeses i necessitats d'aquesta Delegació, com també les quantitats que per subvenir-les heu enviat. Per tant, feu números», carta de Ramon Frontera a Carles Martí i Feced, 22 de juliol de 1939, 24.1.1, doc. 743, ibídem.

97 La continuïtat de les transferències de recursos entre la JARE i la Generalitat també la demostren alguns dels pressupostos i resums de despeses localitzats entre els documents de Josep Tarradellas a Poblet corresponents als darrers mesos del 1940 i als primers del 1941. Després de la invasió nazi, doncs, encara es va poder sostenir durant alguns mesos l'assistència als exiliats. 
de mínims cercant un acord econòmic modest amb el Govern espanyol, que només es va produir mercès a les lluites internes dins del si de la política espanyola republicana. D'aquesta manera, les seves prioritats van ser assegurar-se un nucli d'addictes al voltant de la figura del president mitjançant un sistema limitat de residències pròpies i de subvencions personals, que només va atendre un grup reduït de persones, a la vegada que va intentar protegir l'àmbit de la cultura amb més o menys eficàcia. El resultat d'aquesta línia d'acció va ser que depengués políticament dels organismes espanyols d'un o altre color i que perdés el suport de la militància de base. La invasió alemanya de França, la mort del president Companys i la consegüent dispersió de les forces catalanistes van limitar primer i aturar després les tasques assistencials, de foment de la cultura i de preservació de les institucions fins al punt que va esdevenir pràcticament impossible portar-les a terme en els anys posteriors. El sistema bastit per la Generalitat, humil, de dimensions ajustades i de certa confortabilitat per als organitzadors, va saltar pels aires en un tancar i obrir d'ulls, com tants dels somnis forjats en aquells anys trenta.

\section{Bibliografia}

Balaguer, Josep Maria, i Maria Campillo. 2001. Francesc Trabal: Centenari 1899-1999. Barcelona: Generalitat de Catalunya, Departament de Cultura, Institució de les Lletres Catalanes.

Benet, Josep. 2005. El president Companys, afusellat. Barcelona: Edicions 62.

Benguerel, Xavier. 1971. Memòries, 1905-1940. Madrid/Barcelona: Alfaguara.

Bladé i Desumvila, Artur. 1976. L'exiliada (Dietari de l'exili, 1939-1940). Barcelona: Editorial Pòrtic.

Bosch i Gimpera, Pere. 1980. Memòries. Barcelona: Edicions 62.

Campillo, Maria, ed. 2010. Allez, allez. Escrits de pas de frontera, 1939. Barcelona: L'Avenç.

—.1994. Escriptors catalans i compromís antifeixista (1936-1939). Barcelona: Curial / Publicacions de l'Abadia de Montserrat.

Campillo, Maria, i Francesc Vilanova, ed. 2000. La cultura catalana en el primer exili, 1939-1940: Cartes d'escriptors, intellectuals i científics. Barcelona: Fundació Carles Pi i Sunyer.

Canyameres, Ferran. 1977. El gran sapastre. Barcelona: Agut Editor.

Cirici, Alexandre. 1977. Les hores clares. Barcelona: Edicions Destino. 
Corretger, Montserrat. 2006. «Els intellectuals catalans a Tolosa el 1939 i la represa i organització de la cultura», dins M. Fuentes i F. Tovar, ed. L'exili literari republicà. Tarragona: Publicacions Universitat Rovira i Virgili.

Del Valle, José María. 1976. Las instituciones de la República española en el exilio. París: Éditions Ruedo Ibérico.

Díaz Esculies, Daniel. 1991. El catalanisme polític a l'exili (1939-1959). Barcelona: La Magrana.

— 1993. Entre filferrades: Un aspecte de l'emigració republicana dels Països Catalans (1939-1945). Barcelona: La Magrana.

—_ 1995. L'exili català de 1939 a la República Dominicana. Barcelona: La Magrana.

Esculies, Joan. 2015. Josep Andreu Abelló: Els clarobscurs del catalanisme. Barcelona: Edicions de 1984.

- 2017. Josep Fontbernat: Conseller de Tarradellas. Barcelona: Fundació Irla.

Febrés, Xavier, ed. 1984. Joan Oliver - Pere Calders, conversa transcrita per Xavier Febrés. Barcelona: Editorial Laia.

Gasch, Sebastià. 2001. París, 1940. Barcelona: Quaderns Crema.

Gracia Alonso, Francisco, i Gloria Munilla. 2013. El tesoro del 'Vita': La protección y expolio del patrimonio histórico-arqueológico durante la Guerra Civil. Barcelona: Edicions de la Universitat de Barcelona.

Guillamon, Julià, ed. 2005. Narrativa catalana de l'exili. Barcelona: Galàxia Gutenberg. - 2008. El dia revolt: Literatura catalana de l'exili. Barcelona: Editorial Empúries.

Guinart, Miquel. 1988. Memòries d'un militant catalanista. Barcelona: Publicacions de l'Abadia de Montserrat.

Ibarz, Mercè. 2008. Rodoreda, exili i desig. Barcelona: Editorial Empúries.

Jackson, Gabriel, i Víctor Alba. 2004. Juan Negrín. Barcelona: Ediciones B.

Malló i Vilaplana, Oriol. 2003. Tarradellas: Un segle de catalanisme. Barcelona: Editorial Planeta.

Massot i Muntaner, Josep. 200o. Antoni M. Sbert: Agitador, politic i promotor cultural. Barcelona: Publicacions de l'Abadia de Montserrat.

Mateos, Abdón. 2009. La batalla de México: Final de la Guerra Civil y ayuda a los refugiados, 1939-1945. Madrid: Alianza Editorial.

Mees, Ludger. 2006. El profeta pragmático. Irún: Alberdania.

Miravitlles, Jaume. 1972. Episodis de la Guerra Civil espanyola. Barcelona: Editorial Pòrtic.

Molas, Isidre, ed. 2000. Diccionari dels partits politics de Catalunya: Segle XX. Barcelona: Enciclopèdia Catalana.

Moradiellos, Enrique. 2006. Don Juan Negrín: Una biografia de la figura más difamada de la España del siglo xx. Barcelona: Ediciones Península.

Morales, Mercè. 2012. El Parlament de Catalunya: República, Guerra Civil i exili. Barcelona: Editorial Base.

- 2014. La Generalitat de Josep Irla i l'exili polític català. Barcelona: Editorial Base.

Murià, Anna. 1992. L'obra de Bartra. Assaig d'una aproximació. Barcelona: Editorial Pòrtic. 
Pi i Sunyer, Carles. 1978. Memòries de l'exili: El Consell Nacional de Catalunya, 19401945. Barcelona: Curial.

— 1986. La Guerra, 1936-1939: Memòries. Recopilació i revisió a cura de Núria Pi i Sunyer. Barcelona: Editorial Pòrtic.

- 2000. 1939: Memòries del primer exili. Barcelona: Fundació Carles Pi i Sunyer.

Pous i Pagès, Josep. 2002. Memòries d'exili, edició a cura de M. Àngels Bosch. Barcelona: Editorial Afers.

Preston, Paul. 2014. El final de la guerra. Madrid: Editorial Debate.

Rafaneau Boj, Marie-Claude. 1995. Los campos de concentración de los refugiados españoles en Francia: 1939-1945. Barcelona: Ediciones Omega.

Riba, Carles. 1991-2005. Cartes de Carles Riba, vol. 2 i 4. Barcelona: Institut d'Estudis Catalans.

Rodoreda, Mercè. 1985. Cartes a l’Anna Murià, 1939-1956. Barcelona: Edicions de les Dones.

Roig, Montserrat. 1977. Els catalans als camps nazis. Barcelona: Edicions 62.

Romero Samper, Milagrosa. 2005. La oposición durante el franquismo, vol. 3, El exilio republicano. Madrid: Ediciones Encuentro.

Sánchez Asiaín, José Ángel. 2012. La financiación de la Guerra Civil española. Barcelona: Editorial Crítica.

Sauret, Joan. 1979. L'exili politic català. Barcelona: Editorial Aymà.

Sbert, Antoni Maria. 1940. «Memòria de la Fundació Ramon Llull». Revista de Catalunya [Mèxic], gen., 99-101.

Serrahima, Maurici. 1981. Memòries de la guerra i de l'exili, II: 1939-1940. Barcelona: Edicions 62.

Soldevila, Francesc. 1995. Dietaris de l'exili i del retorn, vol. 1, L'exili. València: Editorial Eliseu Climent.

Solé, Queralt, i Gemma Caballer. 2013. «Aproximación biográfica a Josep Maria Trias i Peitx (Barcelona, 1900 - Prada de Conflent, 1979): un hombre de Unió Democràtica de Catalunya (UDC) clave para el exilio republicano en los campos de internamiento franceses». Pasado y Memoria. Revista de Historia Contemporánea 12 (36): 163-178. doi: https://doi.org/10.14198/PASADO2013.12.06.

Solé i Sabaté, Josep, i Joan Villarroya, dir. 2005. Breu història de la Guerra Civil a Catalunya. Barcelona: Edicions 62.

Trabal, Francesc. 2011. Els contracops de l'enyorança: Escrits de l'exili. Edició i pròleg de Maria Campillo. Sabadell: Fundació La Mirada.

Udina, Enric. 1978. Josep Tarradellas: L'aventura d'una fidelitat. Barcelona: Edicions 62.

Vilanova, Francesc. 1995. Carles Pi i Sunyer (1888-1971). Barcelona: Publicacions de l'Ajuntament de Barcelona.

- 2001. Als dos costats de la frontera: Relacions polítiques entre exili i interior a la postguerra (1939-1948). Barcelona: Publicacions de l'Abadia de Montserrat.

- 2001. «L'ERC de la postguerra: Crisi i davallada», dins Ramon Alquézar et al., Esquerra Republicana de Catalunya. 70 anys d'història (1931-2001). Barcelona: Columna Edicions. 
Vilanova, Francesc. 2004. Viure el primer exili: Cartes britàniques de Pere Bosch $i$ Gimpera i Carles Pi i Sunyer, 1939-1940. Barcelona: Fundació Carles Pi i Sunyer. . 2006. Exiliats, proscrits, deportats. Barcelona: Biblioteca Universal Empúries. . 2007. 1939. Una crónica del año más terrible de nuestra historia. Barcelona: Ediciones Península. . 2010. L’any que va caure París. Barcelona: RBA. 